\title{
EL SINCLINAL DE BENISA-TEULADA. ESTUDIO MORFOESTRUCTURAL E HIDROLÓGICO
}

\author{
Concepción Bru Ronda
}

\section{EL SINCLINAL DE BENISA-TEULADA. ESTUDIO MORFO-ESTRUCTURAL E HIDROLÓGICO}

El sinclinal de Benisa-Teulada ${ }^{1}$ constituye una depresión morfo-estructural abierta almar Mediterráneo por el E., localizada en el litoral N. alicantino, y concretamente en la comarca de la Marina.

Esta cuenca de origen Mioceno se halla disecada por unas corrientes fluviales de carácter intermitente que han dado lugar a una morfología fluvial característica, íntimamente vinculada a una serie de factores. El proceso morfológico resultante tiene como efecto fundamental la erosión de las vertientes.

En este sentido K. J. Gregory y D. E. Walling, (1973)², en un tratado de morfometría aplicada al estudio de la erosión fluvial, consideran una serie de elementos que conforman una cuenca fluvial y que simplifican en tres grupos: 1). Las variables climáticas que constituyen la entrada o imput de energía en el sistema; 2). Las variables inherentes a la cuenca misma, como son las de tipo morfológico, las de tipo lítico y biológico; y 3). Por último las variables de escorrentía, que explican el output de materiales del sistema. Esta visión integradora de los factores que constituyen [148] el conjunto de la cuenca ha servido de base para múltiples estudios y ha sido utilizada para interpretar el sector que nos ocupa.

El estudio de esta zona va a comprender pues el análisis de los elementos de este medio físico como son: clima, geología, estructuras, sistemas de drenaje, y la morfología que, en consecuencia, nos configura todo ello, y que han dado lugar a un modelado natural en el cual se instala el hecho humano. La incidencia antrópica que para Gregory y Walling ${ }^{3}$ quedaría incluida en los elementos biológicos, va a ser en esta depresión de vital importancia para la evolución morfológica de la cuenca, ya que por constituir un medio densamente humanizado, ha sido modificado en la medida de las posibilidades y necesidades antrópicas y ha ejercido tal influencia en el medio, que un proceso geomorfológico en el trazado de la red de drenaje, que son las caputras, ha sido retenido momentáneamente por el hombre en desafío a un medio altamente propicio a estos procesos fluviales, en el estado actual de las condiciones físicas, tanto geológicas como climáticas.

\section{LAS ESTRUCTURAS Y EL MARCO GEOLÓGICO}

Enclavado en la comarca de la Marina, el sinclinal de Benisa-Teulada constituye una estructura desarrollada en un arco litoral abierto al mar Mediterráneo hacia el E., extendido entre

\footnotetext{
${ }^{1}$ Se le ha denominado así por ser éstas las dos poblaciones más importantes del sector, aunque abarca también los núcleos de Calpe, Benitachell y Moraira.

${ }^{2}$ Gregory, K. J. y Walling, D. E. (1973): Drainage basin form and process. A geomorphological approach. Ed. Arnold, London.

${ }^{3}$ Gregory, K. J. y Walling, D. E. Op. Cit.
} 
la Sierra de Benitachell al NE. y el Morro del Toix al SW: este último contrafuerte WNW-ESE que prolonga la sierra de Bernia, agudo anticlinal. El sector queda cerrado a occidente por las estribaciones prebéticas peninsulares que constituyen la prolongación de la unidad de Aitana.

Estructuralmente nos encontramos en el dominio del Prebético meridional alicantino ${ }^{4}$, al N. y fuera del área se instala ya el Prebético externo, del que probablemente el Cap de Sant Antoni sea su limite más oriental ${ }^{5}$.

El influjo estructural del Prebético interno se hace patente en todo el sector y es en buena medida responsable del perímetro costero, siendo altos acantilados y depresiones morfoestructurales la tónica general.

Distinguimos para el sector tres unidades claramente diferenciadas lítica y morfológicamente, pero que intervienen de modo conjunto en el desarrollo del proceso hidrológico. (ver gráfico 1). [149]

1) El retablo montañoso, que comprende unarco, prácticamente continuo, de alineaciones montañosas como la Sierra de Bernia al W, Tosal de Navarro, la Solana de Canor, el Tosal Gros al NW, y el Puig de Benitachell y la Punta de Moraira al NE. Esta continuidad semicircular configura una unidad estructural edificada sobre calizas.

2) La cuenca miocena, formada por las margas burdigalienses, y que abarca las cubetas de Benisa y Teulada, con una orientación SW-NE, y que es cortada por el mar en el WSE.

3) Por último, el litoral, que nos muestra una unidad morfológica, que si bien queda integrada por las anteriores, merece clasificación aparte por el protagonismo morfológico que adquiere individualmente.

El retablo montañoso.- Desde la falla de Bolulla, en el extremo NW y fuera del área, hasta el Mediterráneo, en el Morro del Toix, se desarrolla una alineación montañosa que, genéricamente, denominamos Sierra de Bernia. A lo largo de sus casi $12 \mathrm{Km}$ de longitud, la afilada crestería de Bernia mantiene un arrumbamiento E-S-E constante, contrastando la sencillez de su forma en el paisaje con la complejidad geológica que muestra en los planos generales. Se trata de un anticlinal de base Oligocena-Aquitaniense que soporta una estructura cretáceo-eocena deslizada. El núcleo anticlinal puede verse muy bien a lo largo del Barranco de Mascarat, que corta la estructura de N. a S. entre la Sierra de Toix y la Pedriza, donde las calizas, aquí, pierden la estratificación y pasan a ser una masa compacta triturada. A ambos lados del Barranco, al $\mathrm{Ny}$ al $\mathrm{S}$, las capas vuelven a tener estratificación y buzan $60-80^{\circ}$ en el sur, mientras las capas calizas de la vertiente $\mathrm{N}$ buzan $80^{\circ}$ al norte y contrastan, claramente, con el contacto sinclinal que realizan las margas burdigalienses que buzan $20^{\circ}$ y muestran rumbo WNW.

Elanticlinal cierra por el W violentamente en una especie de cierre periclinal(ensamblaje de la Sierra de Bernia con la del Ferrer) y la prolongación de las capas queda cortada por la falla Bolulla. La dirección NW-SE que mantiene constantemente el anticlinal Oligoceno, es anómala en la tectónica regional, al igual que es curioso el hecho que se da en la crestería de esta sierra donde está el Pico de Bernia $(1128 \mathrm{~m}$ ) que ofrece un magnífico ejemplo de un paquete de calizas lutecienses descansando, limpiamente, sobre la charnela anticlinal del Oligoceno-Aquitaniense. Con ello las crestería mencionada del E y del centro es sustituida por una eocena en la parte occidental, no obstante el aspecto exterior de ambas calizas es el mismo, y la sierra, desde lejos, da la sensación de una crestería homogénea y continua.

Los fenómenos de mantos eocenos deslizados son corrientes en este sector tanto en el flanco $\mathrm{N}$ como en el S de Bernia, e incluso se da la presencia del Cretáceo superior sobre el

\footnotetext{
${ }^{4}$ Rodríguez Estrella, T. (1979).- Geología e hidrología del sector Alcaraz-Lietor-Yeste (Provincia de Albacete). Sintesis geológica de la zona Prebética. Colección de memorias del IGME. 2 vol. Madrid, vol. II, pág. 143.

${ }^{5}$ Rosselló Verger, V. M. (1979): «Los promontorios de la Nau». $1^{\text {er }}$ curso de Geomorfología litoral aplicada. Univ. Politécnica de Valencia, (ETSICCP). Valencia, pág. 87.
} 
Mioceno, dándonos una idea [150] de las tensiones tectónicas y las presiones que han sufrido los distintos paquetes estratigráficos. Por otra parte las fallas que cruzan Bernia de $\mathrm{N}$ a $\mathrm{S}$ son fallas de desgarre, como la del Mascarat.

El anticlinal de la Solana, Tosal Navarro (o Loma Larga), Tosal Gros, constituye un monoclinal que es un espolón de la Sierra de Bernia y que arranca del flanco $\mathrm{N}$ perpendicularmente a ella. Las capas del anticlinal, con dirección SE-NE se curvan desparramándose en abanico para adaptarse por el sur a la dirección de la Sierra de Bernia que es ESE, hecho éste de gran trascendencia por la violencia del encuentro en las direcciones opuestas (ver fig. I). El largo anticlinal se continúa desde Bernia hacia el E en un cierre periclinal hasta el Tosal Gros y se halla formado por los sedimentos oligocenos que en la zona NE se apoyan sobre diversos estratos cretácicos de forma discordante, ello nos indica la preexistencia de una estructura plegada cretácica anterior al Oligoceno y que es la causante de los posteriores desgarres de esta alineación que son atravesados por los barrancos de Teulada (de la Horta) y de la Garganta (Barranco la Aullera). Entre este eje anticlinal y la Sierra de Benitachell se extiende una mancha de materiales miocenos que abren al NE la cuenca miocena de Benisa hacia el sinclinal de Jávea. Tras esta pequeña depresión entre anticlinales se continúa el Puig de Benitachell con clara vergencia $\mathrm{N}$ que se encarga de cerrar la cuenca miocena de Benisa por el E. La orientación general que sigue es ENE-WSW y se encuentran representados en él los pisos del Cretácico superior (Cenomanense y Turonense) que se muestran en la vertiente oriental y en contacto anormal con los materiales oligocenos que se dan en el flanco $\mathrm{W}$ donde los materiales terciarios se yuxtaponen en una sucesión cronológica de capas, representada a modo de vetas en el paisaje a las que han afectado una serie de fracturas relativamente intensas y que alcanzan una expresión morfológica importante por el efecto que, posteriormente, ha desarrollado la erosión diferencial sobre estas estructuras. En el flanco oriental aparece una clara vergencia al N, presentando éste un corte subvertical o vertical con buzamientos tendidos en el flanco que, tras una fractura de gravedad, se sumergen en el Mediterráneo. La geometría de este anticlinal es claramente prebética, excepcionalmente sencilla y que aparece en el sector oriental truncada por un sistema de fallas de desgarre, cuya actividad se ha desarrollado en distintas fases (fallas de la punta de Moraira).

El sinclinal mioceno.- Abarca esta estructura una cuenca miocena extendida entre Benisa y Teulada. Se halla articulada entre los anticlinales anteriormente descritos, y rellenada de materiales miocenos de facies «Tap» discordantes con el Oligoceno, e involucrados en el constreñimiento de las estructuras. [151]

Este amplio sinclinal, de eje SW-NE, presenta cerca de $10 \mathrm{Km}$ de anchura en su punto más amplio y unos 15 o más Km de longitud y en él se acumulan grandes espesores de depósitos burdigalienses que, en su máxima potencia, sobrepasan los $1500 \mathrm{~m}$.

En el sector SW de la cuenca miocena, ésta toma el nombre de sinclinal de Calpe, quedando limitado al SW por la Pedriza y el Morro de Toix, que lo retienen en este sector, y toma la misma orientación que esta sierra (ESE) buzando hacia el N $30^{\circ}$, en el contacto con la serie oligocena. Presenta aquí el sinclinal $1100 \mathrm{~m}$ de espesor e incluso más.

El eje sinclinal se extiende bajo la Sierra de Oltá (testigo eoceno deslizado sobre las margas) y ya en la zona de Benisa el sinclinal alcanza la mayor profundidad, concretamente, a $3 \mathrm{Km}$ al W de dicho pueblo, señalándose en superficie por un desorden de las capas miocenas, ya que al plegarse el sinclinal, en sus capas más profundas por el efecto subsidente, lo hacen de forma concéntrica y por ello, los estratos más altos sufren compresiones y pequeñas dislocaciones que dan un plegamiento disarmónico del eje sinclinal en esta zona.

El sinclinal se extiende en sentido NE hasta llegar a la Sierra de Benitachell, en donde el contacto que realiza el borde NE del sinclinal margoso con este anticlinal es mucho más abrupto que en el contacto SW, dándose en este contacto la presencia de capas verticales y hasta 
volcadas con buzamientos de $80^{\circ} \mathrm{S}$. Como se ve, los estratos del eje mayor (SW-NE) pinzan hacia el interior, hacia la zona de máximo espesor.

Sobre el burdigaliense y discordantes se da la presencia de lastrones de suelos molásticos vindobonienses que se muestran, únicamente, en pequeños y escasos retazos muy localizados en la zona situada al S de Benisa y al NE de Teulada. El contacto con la base oligocena se realiza en muchas ocasiones mediante depósitos de margo-calizas (Flysch) maciños y molasas con fauna burdigalienses y aquitamienses que, en algunos tramos, presenta importancia suficiente y características definidas.

Por último, un hecho a señalar es la presencia sobre la estructura sinclinal de una serie de anticlinorios o retazos eocenos, como son la Sierra de Oltá, el Peñón de Ifach y los pequeños tozales de Concentari (estos últimos disgregados del núcleo original de Oltá). Asentadas estas estructuras calizas sobre el yacente Mioceno, son los testigos, en la cuenca miocena, de un hipotético manto de corrimiento, relacionado con el Trias, el cual aparece a poniente de la Sierra de Oltá.

El sector litoral.- Las estructuras litorales comienzan al NE, con los paquetes cretácicos que presentan una potencia de varios centenares de metros y facies calizas o calcáreo-margosas que corresponden al gran arco hundido del Puig de Benitachell, que realiza el contacto con el Cabo de San Antonio mediante una falla inversa. Todo este sector se [152] encuentra muy tectonizado, y la costa presenta acantilados subverticales. Hacia el sur destaca la Punta de Moraira con $162 \mathrm{~m}$ y que avanza como $1 \mathrm{Km}$ mar adentro hacia el S presentando una disimetría acusada de pendientes entre el flanco $\mathrm{W}$ y el $\mathrm{E}$, siendo el primero más accesible ${ }^{6}$.

Todo este sector de costa queda adscrito según la clasificación del profesor Roselló ${ }^{7}$ dentro de las costas de acantilado alto, superando en este sector el cantil los $150 \mathrm{~m}$.

$\mathrm{Al}$ flanco W de la Punta de Moraira, más suave, le sucede la pequeña playa del Portet, donde la costa es baja y comienza a estar labrada sobre el sinclinal mioceno y el Flysch inferior. Siguiendo al W y en la carretera que va del caserío del Portet a Moraira aparece un cantil algo más elevado, afectado por una falla que corta, paralelamente a la costa, el Flysch más deleznable. Pasado el puerto, hoy deportivo, de Moraira se hunde la costa en una depresión morfoestructural miocena, que coincide con amplios valles que penetran hacia el interior y que forman, en la costa, la ensenada de Moraira con la presencia de una playa arenosa, la de l'Ampolla, así denominada por la formación albufereña que alberga.

La línea de costa que aquí pertenece al tipo acantilado bajo, se sucede hacia el SW de la ensenada de nuevo con un frente cortado en el Flysch en la zona de l'Andrago y Cap Blanc, donde los cauces de torrentes suspendidos conforman pequeñas calas pertenecientes a un litoral de costas de acantilado medio.

A poniente de Cap Blanc, la costa apenas se eleva y se reduce a peñas calcáreas que forman humildes cerros hasta el Penyal de Ifach que «muestra un gigantesco mogote calizo esculpiendo aquí en un retazo eoceno de Oltá, abrupto por todos los lados, especialmente por el NW y S, la caída vertical se continúa hasta la isobata $-15 \mathrm{~m}$ en ambos lados. Los $332 \mathrm{~m}$ de altitud justifican su inclusión en el tipo de litoral de acantilado alto» ${ }^{8}$.

Ya en la ensenada de Calpe, que comprende otra depresión morfoestructural, encontramos sobre el burdigalense de nuevo una costa baja donde se localizan playas de arena. Hacia el SW el litoral vuelve a superar los 200 m de elevación en la Sierra de Morro del Toix.

\footnotetext{
${ }^{6}$ Rosselló Verger, V. M. Opus cit. Pág. 91.

7 Rosselló Verger, V. M. (1978): «Un variado litoral» en Geografia de la Provincia de Alicante. Excma. Diputación Provincial de Alicante. Pág. 21.
}

\footnotetext{
${ }^{8}$ Rosselló Verger, V. M. (1978). Opus cit. Pág. 22.
} 


\section{TECTOGÉNESIS Y GEOLOGÍA}

En relación a la tectónica hay que partir de la base que pertenecientes [153] a la etapa preorogénica se produjeron unas fallas de zócalo en la cobertera, constituyendo unas áreas de flexura que marcaron los límites entre facies subbéticas y potenciaron las series; estas áreas de flexura constituyeron puntos débiles en los que el Trias pudo actuar preferentemente, dando lugar a zonas levantadas y franjas diapíricas embrionarias. Relacionado con estos movimientos ascensionales verticales del Trias, se dieron fenómenos de discordancias locales y deslizamientos gravitacionales submarinos ${ }^{9}$. Sin embargo, la historia geológica de la zona se muestra a partir de finales del Jurásico o principios del Cretácico, así aunque la sedimentación triásica queda evidenciada en la zona, los tramos inferiores del Jurásico son mal conocidos y encontramos únicamente en superficie de la sedimentación mesozoica al Cretácico superior que se muestra en los pisos que contornean el cierre montañoso de toda la cuenca miocena, donde vemos al cenomanense, turonense y senoniense.

La transición del Cretácico superior al eoceno y posteriormente al oligoceno ofrece una enorme laguna en esta zona, pasando desde el senoniense inferior al oligoceno sin ninguna sedimentación intermedia, mediante un contacto anormal. Esto se debe a la fase terminal del eoceno y principios del Oligoceno, donde empujes N-S deforman los sedimentos, hasta ahora en tranquilidad, y crean las primeras diferencias de relieve. Esto guarda relación con las áreas de flexura a las que se aludió. Éstas inestables y de cambios estratigráficos importantes al sobrevenir la etapa orogénica, fueron las más vulnerables a fracturarse y desplazarse hacia el N, de ahí que se asienten en ellas los cabalgamientos importantes y desplazamientos hacia el $\mathrm{N} \mathrm{a}$ veces de 15 a $30 \mathrm{Km}$, cabalgamientos que coincidirían con la separación de distintos dominios paleográficos.

La tectónica mesoalpina va a ser la primera fase de plegamiento (Chantiense superior-Aquitaniense inferior) y será la responsable de las discordancias e hiatos sedimentarios y erosivos entre el oligoceno y la serie cretáceo-eocénica. En conjunto, se aprecian oscilaciones del nivel de fondo más que procesos orogénicos. Esto ocurre sobre todo durante el cretáceo y el eoceno, sin embargo será a finales del eoceno cuando la región sufra una verdadera orogenia.

La sierra de Bernia en esta época no existe, aunque ya en su lugar se ven las directrices NW-SE y se adivina un flanco buzando hacia el sur de un anticlinal externo, sobre lo que hoy es la cubeta miocena de Benisa. Esta potente cuenca aparece aquí como un anticlinal cretáceo arrasado. [154]

La tectónica oligocena afectó a las capas profundas en general del cretáceo, que adquirieron relativa rigidez, especialmente en algunos lugares, y reaccionaron en general en forma de fractura sin perder sus primitivas directrices orogénicas.

El mar ocupó toda la zona hasta finales del Mioceno, llegando en este periodo hasta el actual retablo montañoso al NW (Tosal Cao, Tosal Gros y toda la alineación que en él se integra) y aunque no configurando el eje anticlinal, los materiales cretácicos y los oligocenos posteriormente depuestos formaban un macizo a modo de umbral. Ya en el Mioceno el mar transgresivo dejó a su paso los depósitos burdigalienses que alcanzaron grandes espesores, sobre los $1500 \mathrm{~m}$ en los sectores de mayor profundidad. La acumulación de estos abundantes depósitos margosos y margo-calizos, junto a reajustes isostáticos que acompañaron a la orogenia estaírica, producen la subsistencia del sinclinal Benisa-Teulada, así como por un efecto de desplazamiento del trias infrayacente, se produce a finales del Mioceno la eclosión diapírica.

Acaece así la tectónica neoalpina con los movimientos estaíricos, serán éstos los más importantes, desarrollándose entre el Oligoceno y el Mioceno inferior. Esta orogenia es la que,

\footnotetext{
${ }^{9}$ Rodríguez Estrella, T. (1979). Opus cit. Pág. 234.
} 
en parte, da la configuración actual a la zona, ya que es responsable del plegamiento de las series miocenas, y conjuntamente de las mesozoicas eocenas. La importancia de estos movimientos más que la orogenia en sí viene caracterizada por dos movimientos isostáticos de signo contrario: a) hundimiento de la cuenca miocena, y b) elevación del diapiro triásico de Altea, situado al SE de la zona y que va a afectar a este sector también.

La banda de separación entre estas dos zonas sigue el eje actual de Bernia, que se encuentra en las áreas isostáticas de signo contrario, siendo la línea preferente para el progreso del diapiro hacia el $\mathrm{W}$.

Los movimientos verticales diapíricos ocasionaron la formación del anticlinal terciario del borde de Bernia, así como del anticlinal terciario que se extiende a través de la Solana, el Tosal Navarro, Tosal Gros y Puig de Benitachell. Este conjunto anticlinal de origen terciario recubre a distintos macizos cretáceos que subyacen y que se ven enlazados por él. Estos macizos cretáceos de fondo presentan una serie de fracturas, casi con seguridad anteterciarias, por lo que encontramos una estructura plegada cretácica discordante sobre el yacente superior Oligoceno y Mioceno. Estos depósitos oligocenos que forman los anticlinales antes citados, terciarios, configurados a raíz de la orogenia diapírica, sufren, por la misma acción de los diapiros, una serie de fracturas radiales, en parte, nuevas y originales, o también, guiadas por las antiguas estructuras y líneas de debilidad cretácicas, apareciendo las fallas del diapiro de Altea en la Sierra de Bernia, como la que cruza a ésta por el antiguo fuerte [155] de Bernia y que se prolonga, con otro carácter, por el oriente de la Sierra del Ferrer y la de Toix.

El buzamiento de los planos de falla varía desde los $43^{\circ}$ hasta $\operatorname{los} 80^{\circ}$. Las direcciones de las fallas son, generalmente, SE-NW y, dado su carácter de fallas de distensión normales y posorogénicas, no se amoldan a las directrices de plegamiento mioceno que en la zona es, constantemente, NE-SW. Algunas de estas fallas se prolongan bajo el Mioceno sin afectarlo mayormente y son fosilizadas por él.

Volviendo al sinclinal Benisa-Teulada, el cual se encontraba sometido a un proceso de subsidencia, también sufre un plegamiento y los bordes y sus capas más profundas lo hacen concéntricamente, por lo que los estratos más altos padecen compresiones y pequeñas dislocaciones y repliegues, con lo que el sinclinal, que es una cubeta alargada, y los extremos del eje mayor (SW-NE) pinzan hacia el interior, hacia la zona de máximos espesores.

La superficie de depósitos margosos que fue afectada por la subsidencia, integraba toda una extensa área que hoy queda, parcialmente, recubierta por el Mediterráneo y cuyo límite occidental está ahora formado por la Solana y el Tosal Gros.

A finales del Mioceno, principios del Plioceno, será cuando el mar se retire de estas zonas, produciéndose, entonces, regresiones marinas de considerable amplitud y duración, dándose una baja de nivel marino del Terciario superior coincidiendo con la aludida «cuasi» desecación del Mediterráneo en época messiniense, es decir, finimiocena. En el Plioceno, el mar ha abandonado totalmente la región y comienza a tomar la costa una forma accidentada por la existencia de los promontorios calizos formados a raíz de los movimientos diapíricos y neoalpinos, así como por la presencia de los depósitos margo-calizos que presentan en este sector litoral SE un flanco muy abrupto hacia el mar. Momento propicio para que se instalen los primeros atisbos de circulación hídrica que se dará durante todo el Plioceno.

Por último, una fase de plegamiento suave que se caracteriza para la región levantina y que afectó a este sector es una tectónica reciente y posterior a los desgarres antes mencionados, que según Montenant $\mathrm{y}$ Echalier, se atribuyen a edad post-pliocena superior $\mathrm{y}$ post-villafranquiense ${ }^{10}$.

${ }^{10}$ Montenant, B. (1971). «Pliocene superieur et Villafranchien dans le Levant espagnol (Murcie-Alicante)». Bol. Geol. Min. Tomo XXXII-I, págs. 52-58. 
Característico este plegamiento para la región costera mediterránea [156] va a dar lugar a pliegues y fallas inversas de desgarre levogiras, algunas de ellas ya existentes en el Mioceno, todas ellas de dirección NE-SW ${ }^{11}$, y que va a provocar el basculamiento del sinclinal margoso en su sector SE.

Se suceden al igual en el Pleistoceno final las múltiples fracturas que afectan a los anticlinales calizos y al flysch costero produciendo los acantilados medios y altos. Estas pulsaciones tectónicas no hay que abandonar la idea de que se relacionan con las fallas de zócalo paleogeotectónicas que han venido manifestándose en las distintas fases tectónicas, y que se han reactivado en una etapa reciente, e incluso juegan en la actualidad, prosiguiendo estas pulsaciones durante todo el cuaternario hasta nuestros días. Si bien durante el cuaternario prosigue la ya iniciada elevación de la zona, dándose como resultado el encajonamiento de la red fluvial $^{12}$. Esta red fluvial partirá ahora desde una nueva divisoria de aguas.

\section{ASPECTOS CLIMÁTICOS}

La caracterización climática de esta cuenca en base al conocimiento de un tiempo estadístico mediante el análisis de cifras medias nos define un clima litoral mediterráneo subárido, con totales pluviométricos reducidos y temperaturas altas. Sin embargo, esta clasificación puede llevar a confundir acerca de la efectividad de este clima sobre áreas geográficas como las que nos ocupa, las cuales ofrecen paisajes geomorfológicos complicados y muy evolucionados debido a la acción de las aguas de arroyada, no cuadrando este hecho con una definición tan generalizada de clima mediterráneo. Asimismo los efectos de la dinámica atmosférica general sufren matizaciones que introducen peculiaridades al sector. Los datos climáticos analizados pertenecen al observatorio de Benisa- convento, y corresponden a un período de 25 años (1955-1979) para las precipitaciones y una serie de 11 años (1969-1979) para las temperaturas. El centro meteorológico se encuentra situado en el altiplano de Benisa, a 300 $\mathrm{m}$ sobre el nivel del mar, y a unos $6 \mathrm{Km}$ de la costa, por lo que las variaciones en función de la altitud y continentalidad pueden darse en algún punto de la cuenca, entre la costa y el altiplano, no obstante la inexistencia de una pantalla orográfica que se interponga entre estos dos puntos del sinclinal unifica las influencias.

El tratamiento estadístico exhaustivo de estas series de datos, y particularmente [157] en lo que se refiere a las precipitaciones que se han tratado día a día, revelan la existencia de unos fenómenos climáticos que escapan al análisis de cifras medias, las cuales enmascaran la realidad. Con ello se llega a la comprensión de procesos morfogenéticos que se dan en esta zona y que guardan una estrecha relación con la climatología imperante. Un hecho pues en el que se va a hacer hincapié es la importancia de las precipitaciones de fuerte intensidad horaria y su incidencia en los relieves, dada la frecuencia con que se producen. Estudios climáticos regionales han permitido poner de manifiesto diferencias y evoluciones en el clima del sector, que han servido para contrastar aspectos dinámicos y estadísticos ${ }^{13}$.

${ }^{11}$ Rodríguez Estrella, T. (1979). Op. cit. Págs. 257-258.

${ }^{12}$ Rodríguez Estrella, T. (1979). Op. cit. Pág. 261.

${ }^{13}$ Estudios de clima; 1.- López Gómez, A. (1955): «La corriente en chorro y las perturbaciones atmosféricas». Estudios Geográficos, Vol. XVI, no 59, pp. 279-366. 2.- Jansa, J. M. (1962): «El frente mediterráneo», Geofísica, Vol. XXI, pp. 249-259. 3.- Lautensach, H. (1964). Geografia de España y Portugal. Barna. Ed. Vicens Vives, 814 pp. 4.- Kunov, P. (1966). El clima de Valencia y Baleares. Fac. de Filosofía y Letras. Institución Alfonso el Magnánimo. Valencia. 5.- Clavero, P. L. (1977). Los climas de la región valenciana. Tesis doctoral. Fac. de Geografía e Historia. Universidad de Barcelona. 548 pp. 6.- Quereda, J. (1978). Comarca de la Marina. Alicante. Estudio de Geografia regional. Alicante, Excma. Diputación Provincial de Alicante. 434 pp. 
La dinámica atmosférica.- Al realizar brevemente un examen de la circulación atmosférica a la que se encuentra sujeta el área de estudio, hay que destacar una serie de hechos de gran trascendencia para ella. En primer lugar, la inserción dentro de la Península Ibérica le confiere una situación latitudinal en el borde inferior de la zona templada, en la zona de circulación general del $\mathrm{W}$, y en la vecindad de las altas presiones subtropicales, cuya manifestación de las mismas se concreta en la presencia del anticiclón de las Azores. En segundo lugar, desempeña un papel importante la posición del área de estudio respecto de la Península en su borde oriental y respecto a la presencia inmediata del Mediterráneo ${ }^{14}$, que cumple la función esencial de reservorio de agua y calorías. Por último la repercusión en la dinámica de los relieves de las tierras ribereñas del Mediterráneo que implican modificaciones climáticas, tanto de orden local como hechos climáticos de proyección mucho mayor al configurarse este mar como una cuenca cerrada por los altos relieves que delimitan a las tierras litorales de las del interior.

La importancia del Mediterráneo como reservorio de agua y calorías va a ser un factor básico, ya que este mar cumple la función de administrador de ambos elementos a la atmósfera, siendo ésta una premisa fundamental para que se produzcan precipitaciones. Así este mar presenta unas altas tensiones de vapor, que influyen principalmente durante [158] las variaciones estacionales de otoño y primavera coincidiendo con ellas las lluvias más importantes. A ese hecho principal de las altas tensiones de vapor y con la presencia de bajas desprendidas o gotas frías al altura, se producen lluvias torrenciales de gran violencia y fuerte intensidad que tienen un gran poder morfogenético en momentos en que a nivel de superficie apenas se presienta depresión alguna.

Gran importancia alcanza este reservorio de calorías en lo que concierne a la revitalización de las borrascas del frente polar derivado que al contrastar el aire continental frío y seco con el cálido y húmedo del Mediterráneo desarrolla un frente mediterráneo ${ }^{15}$, originado por el choque de estas dos masas de aires de propiedades físicas tan contrastadas. El choque puede ser tan violento que no es raro apreciar cómo un frente atlántico en vías de extinción se regenera enérgicamente al caer en nuestra cuenca, cuando ya en el Atlántico sus residuos han desaparecido. Estos fenómenos de borrascas revitalizadas, junto con los procesos de gota fría en altura, son los que incrementan enormemente los totales pluviómetros de esta área.

Factores geográficos locales del sector que nos ocupa interfieren matizando o aumentando los efectos de esta circulación general. La posición a sotavento del retablo montañoso que la envuelve propicia más aún el resguardo de la zona respecto de los vientos del $\mathrm{W}$, mientras que por la marcada orientación de la costa hacia el NE favorece la acción de las advecciones del NE. Igualmente con ocasión de fenómenos de gota fría en altura, las advecciones del Levante con aire cálido e inestable aportan la mayoría de los totales pluviométricos. Influye asimismo la cercanía del mar en la acción moderadora de las temperaturas, que mantienen una media muy regular en torno a los $16^{\circ}$.

Las precipitaciones.- Rasgos característicos del régimen de precipitaciones de este sector es la moderada pluviometría y su gran irregularidad interanual. Los valores medios señalan para la serie de 25 años (1955-1979) una precipitación media anual de 543,9\% mm, situándose con ello en un lugar de transición dentro de la división que realiza el profesor Clavero Paricio entre la llanura litoral lluviosa (con $641,0 \mathrm{~mm}$ ) y el sector litoral meridional $(306,0 \mathrm{~mm}$ ) si bien él la

\footnotetext{
${ }^{14}$ Clavero, P. L. (1980). Los climas de la región valenciana. Resumen Tesis Doctoral. Servicio de Publicaciones, Universidad de Barcelona. Pág. 12.

${ }^{15}$ Jansa, J. M. (1962). Op. cit.
} 
conceptúa como periférica de la fachada lluviosa del Macizo de Alcoy ${ }^{16}$; aunque la media de las precipitaciones de la serie es de 543,9 $\mathrm{mm}$, presentan los totales anuales una marcada irregularidad interanual que es el rasgo fundamental de este clima, lo que constituye un grave obstáculo para la geografía humana, y en concreto, para las actividades agrícolas que en este sector [159] de explotación vitivinícola se ha adaptado a la morfología de abancalamientos, impuesta por el clima, con un trabajo colosal en el intento de regularizar las vertientes excavadas $\mathrm{y}$, totalmente, invadidas por redes de barrancos que, al actuar, poseen un gran poder destructivo, en base a estas esporádicas e irregulares actuaciones.

Índice del alcance de este fenómeno de irregularidad interanual es el recorrido y coeficiente de irregularidad.

\begin{tabular}{|c|c|c|c|c|}
\hline & Año más & & Coef. & \\
\hline Estación & abundante & Año más seco & Irreg. & Recorrido \\
\hline Benisa & $907^{\prime} 9 \mathrm{~mm}$ & $267^{\prime} 0 \mathrm{~mm}$ & $3{ }^{\prime} 4$ & $640^{\prime} 8$ \\
\hline
\end{tabular}

De ello se deduce que la precipitación caída en el año más abundante de la serie es 3,4 veces superior a la registrada en el año más seco de la misma.

En lo concerniente a la distribución mensual de las precipitaciones, se tiene un máximo absoluto para este sector durante el mes de octubre $(109,06 \mathrm{~mm}$ valor medio del período) y aparece otro máximo relativo, menos importante que el de octubre en el mes de diciembre con $72,75 \mathrm{~mm}$ de valor medio; de ese modo se observa que el máximo pluviométrico corresponde a otoño e invierno, siendo el verano la estación seca caracterizada y en primavera el mínimo secundario (con 48,37 mm en abril de precipitación media). En verano se registran los valores mínimos, con mínimo absoluto en el mes de julio $(7,14 \mathrm{~mm})$ cuyo valor medio raramente supera $\operatorname{los} 15 \mathrm{~mm}$. Tanto junio como agosto registran precipitaciones de carácter tormentoso, algunas de las cuales llegan a ser importantes, como la de junio de 1960 con 173,5 mm de los cuales 113,0 cayeron el día 8. El mes de mayor precipitación absoluta fue el de octubre de 1971 con $244,0 \mathrm{~mm}$ de precipitación total. El coeficiente entre los meses de mayor y menor precipitación da valores muy elevados para este sector, siendo éste de 15,2. No obstante, es más exacto calcular el coeficiente pluviométrico relativo de A. Angot, que tiene en cuenta las diferencias posibles por la distinta duración de los meses.

\section{CUADRO}

Coeficiente de las precipitaciones mensuales según A. Angot para la estación de Benisa (Convento).

$\begin{array}{llllllllllll}\underline{\text { En. }} & \underline{\text { Fb. }} & \underline{\text { Mar. }} & \underline{\text { Ab. }} & \underline{\text { May. }} & \underline{\text { Jun. }} & \underline{\text { Jul. }} & \underline{\text { Ag. }} & \underline{\text { Set. }} & \underline{\text { Oc. }} & \underline{\text { Nov. }} & \underline{\text { Dic. }} \\ \text { 1'17 } & \text { 0'91 } & \text { 0'93 } & \text { 1'08 } & \text { 0'84 } & \text { 0'55 } & \text { 0'15 } & \text { 0’31 } & \text { 0’74 } & \text { 2'36 } & \text { 1'33 } & \text { 1'57 }\end{array}$

Se observa así el reparto estacional de las precipitaciones y se aprecia que el máximo otoñal se prolonga hacia un máximo secundario en [160] invierno, que decae en febrero. El máximo otoñal queda bien definido en octubre e, igualmente, se marca la disminución estival en los reducidos porcentajes que van de junio a septiembre. Los valores inferiores a la unidad son en general los mayores, dando un largo período árido que coincide con los meses anteriores

\footnotetext{
${ }^{16}$ Clavero Paricio, P. L. (1980). Op. cit. Pág. 63.
} 
y posteriores al verano.

El reparto estacional de las lluvias se realiza de la siguiente forma para el año medio:

$\begin{array}{ccccc} & \text { Primavera } & \text { Verano } & \text { Otoño } & \text { Invierno } \\ & 1300^{\prime} 37 \mathrm{~mm} & 46^{\prime} 53 \mathrm{~mm} & 202^{\prime} 14 \mathrm{~mm} & 1644^{\prime} 77 \mathrm{~mm} \\ \% \text { PA } & 233^{\prime} 9 & 8^{\prime} 5 & 37^{\prime} 16 & 30^{\prime} 2\end{array}$

que implican los tantos por ciento correspondientes al volumen de precipitaciones respecto del total medio anual. Cuadrando este reparto con los meses medios que presentan mayor número de días con precipitación:

$\begin{array}{llllllllllll}\text { Ene. } & \underline{\text { Feb. }} & \underline{\text { Mar. }} & \underline{\text { Ab. }} & \underline{\underline{\text { May }}} & \underline{\text { Jun. }} & \underline{\text { Jul. }} & \underline{\text { Ag. }} & \underline{\text { Set. }} & \text { Oct. } & \text { Nov. } & \text { Dic. } \\ \text { 3'6 } & \text { 3'2 } & \text { 3'3 } & \text { 3'9 } & \text { 3'0 } & \text { 2'2 } & \text { 0'5 } & \text { 1'2 } & \text { 2'5 } & \text { 5'0 } & \text { 3'3 } & \text { 4'4 }\end{array}$

Respecto a los días de todo un año, se producen grandes oscilaciones entre los distintos valores anuales no siendo una media de días muy orientativa. Además, el incremento o reducción del número de días de precipitación no están en concordancia con el aumento o disminución de la precipitación total. Así en 1979, con 59 días de lluvia cayeron 366,3 mm, mientras que en 1971 se registraron $907,8 \mathrm{~mm}$, que se repartieron en 55 días, existiendo en la serie estudiada otros ejemplos.

A lo largo del estudio de precipitaciones que venimos haciendo, un hecho claro a la vez que problemático en este régimen climático es la irregularidad interanual. Por ello, vamos a aproximarnos más a la realidad examinando valores diarios y absolutos y dejando aparte los valores medios.

Cada año no viene repartido con unas lluvias homogéneas a lo largo del mismo, en cada una de sus estaciones, sino que más bien la precipitación anual atiende a totales mensuales que alcanzan valores máximos y, además, concentrados en pocos días. Siendo así, el mes de mayores precipitaciones, el mes decisivo para dar el total anual suponiendo hasta un $26 \%$ de las lluvias anuales.

Porcentaje del mes de máxima precipitación respecto del total anual. [161]

\begin{tabular}{llllll}
$\frac{\text { Año }}{P(\mathrm{~mm})}$ & $\underline{\text { Mes }}$ & $\underline{P(\mathrm{~mm})}$ & $\underline{\text { \%total }}$ & $\underline{N^{o} \text { días }}$ \\
1955 & $548^{\prime} 0$ & $\mathrm{I}$ & $126^{\prime} 0$ & $22^{\prime} 9$ & 1 \\
1956 & $560^{\prime} 0$ & $\mathrm{X}$ & $208^{\prime} 0$ & $37^{\prime} 1$ & 7 \\
1957 & $836^{\prime} 1$ & $\mathrm{X}$ & $284^{\prime} 5$ & $34^{\prime} 0$ & 7 \\
1958 & $862^{\prime} 0$ & $\mathrm{X}$ & $302^{\prime} 0$ & $35^{\prime} 0$ & 9 \\
1959 & $688^{\prime} 5$ & $\mathrm{II}$ & $143^{\prime} 0$ & $20^{\prime} 7$ & 10 \\
1960 & $570^{\prime} 6$ & $\mathrm{VI}$ & $173^{\prime} 5$ & $30^{\prime} 4$ & 4 \\
1961 & $324^{\prime} 5$ & $\mathrm{XI}$ & $96^{\prime} 0$ & $29^{\prime} 5$ & 3 \\
\hline
\end{tabular}




$\begin{array}{lccccc}1962 & 676^{\prime} 7 & \text { X } & 132^{\prime} 0 & 19^{\prime} 5 & 4 \\ 1963 & 361^{\prime} 0 & \text { XII } & 175^{\prime} 5 & 48^{\prime} 6 & 12 \\ 1964 & 359^{\prime} 5 & \text { XII } & 150^{\prime} 0 & 41^{\prime} 7 & 6 \\ 1965 & 434^{\prime} 5 & \text { X } & 128^{\prime} 0 & 29^{\prime} 4 & 9 \\ 1966 & 267^{\prime} 0 & \text { X } & 149^{\prime} 0 & 55^{\prime} 8 & 7 \\ 1967 & 654^{\prime} 1 & \text { II } & 277^{\prime} 5 & 42^{\prime} 4 & 8 \\ 1968 & 434^{\prime} 0 & \text { XII } & 105^{\prime} 5 & 24^{\prime} 3 & 8 \\ 1969 & 658^{\prime} 7 & \text { IV } & 153^{\prime} 2 & 23^{\prime} 2 & 8 \\ 1970 & 354^{\prime} 1 & \text { X } & 116^{\prime} 5 & 32^{\prime} 9 & 8 \\ 1971 & 907^{\prime} 8 & \text { X } & 352^{\prime} 0 & 38^{\prime} 7 & 10 \\ 1972 & 306^{\prime} 7 & \text { III } & 77^{\prime} 6 & 25^{\prime} 3 & 6 \\ 1973 & 831^{\prime} 6 & \text { III } & 143^{\prime} 7 & 17^{\prime} 2 & 5 \\ 1974 & 404^{\prime} 4 & \text { X } & 143^{\prime} 0 & 35^{\prime} 3 & 3 \\ 1975 & 487^{\prime} 2 & \text { III } & 160^{\prime} 0 & 32^{\prime} 8 & 7 \\ 1976 & 415^{\prime} 0 & \text { V } & 87^{\prime} 5 & 21^{\prime} 0 & 8 \\ 1977 & 759^{\prime} 4 & \text { V } & 139^{\prime} 1 & 18^{\prime} 3 & 8 \\ 1978 & 527^{\prime} 0 & \text { X } & 169^{\prime} 0 & 32^{\prime} 0 & 5 \\ 1979 & 366^{\prime} 3 & \text { I } & 94^{\prime} 8 & 25^{\prime} 8 & 12\end{array}$

El período más favorable para estas lluvias es el de septiembre a octubre, pero puede recaer, también, en otro mes del año y hacerle pasar a ser el mes máximo en función de uno o varios días de fuertes lluvias. Así, en 1967, el mes de febrero totalizó 277,5 mm pasando a ser el mes máximo para dicho año, representando un $23,9 \%$ del total anual.

Aún podemos concretar más viendo cómo sólo pocos días marcan la pauta de todo un año, desde el punto de vista de las precipitaciones, con unos totales muy abundantes en pocas horas. Analizando, pues, el día de máxima precipitación anual, nos da una idea clara del fenómeno, incluso, este día de máxima precipitación puede representar en varios años, sucesivos o distintos, una tercera o cuarta parte del total de precipitaciones anuales. [162]

\begin{tabular}{ccccc}
$\underline{\text { Año }}$ & $\underline{\text { Mes/Día }}$ & $\underline{\text { Máx. en } 24 h .}$ & $\underline{P . A .}$ & $\underline{\%}$ \\
1955 & $\mathrm{I} / 25$ & $126^{\prime} 0 \mathrm{~mm}$ & $548^{\prime} 0$ & $22^{\prime} 9$ \\
1956 & $\mathrm{X} / 11$ & $66^{\prime} 0 \mathrm{~mm}$ & $560^{\prime} 0$ & $11^{\prime} 7$ \\
1957 & $\mathrm{XII} / 27$ & $90^{\prime} 0 \mathrm{~mm}$ & $836^{\prime} 1$ & $10^{\prime} 7$ \\
1958 & $\mathrm{X} / 27$ & $123^{\prime} 0 \mathrm{~mm}$ & $862^{\prime} 0$ & $14^{\prime} 2$ \\
\hline
\end{tabular}




\begin{tabular}{|c|c|c|c|c|}
\hline 1959 & $\mathrm{~V} / 8$ & $55^{\prime} 0 \mathrm{~mm}$ & $688^{\prime} 5$ & $7 ’ 9$ \\
\hline 1960 & XII/17 & $115^{\prime} 0 \mathrm{~mm}$ & $570 ’ 6$ & $20 ’ 1$ \\
\hline 1961 & $\mathrm{XI} / 1$ & $64^{\prime} 0 \mathrm{~mm}$ & $324^{\prime} 5$ & $19^{\prime} 7$ \\
\hline 1962 & $\mathrm{X} / 16$ & $75^{\prime} 0 \mathrm{~mm}$ & $676^{\prime} 7$ & $11^{\prime} 0$ \\
\hline 1963 & IX/4 & $58^{\prime} 0 \mathrm{~mm}$ & $361^{\prime} 0$ & $16^{\prime} 0$ \\
\hline 1964 & XII/12 & $70^{\prime} 0 \mathrm{~mm}$ & $359 ’ 5$ & $19^{\prime} 4$ \\
\hline 1965 & $\mathrm{XII} / 9$ & $63^{\prime} 0 \mathrm{~mm}$ & $434^{\prime} 5$ & $14^{\prime} 4$ \\
\hline 1966 & $\mathrm{X} / 5$ & $64^{\prime} 0 \mathrm{~mm}$ & $267^{\prime} 0$ & 23 '9 \\
\hline 1967 & $\mathrm{II} / 11$ & $98^{\prime} 5 \mathrm{~mm}$ & $654^{\prime} 1$ & $15^{\prime} 0$ \\
\hline 1968 & $\mathrm{~V} / 10$ & $70^{\prime} 0 \mathrm{~mm}$ & $434^{\prime} 0$ & $16^{\prime} 1$ \\
\hline 1969 & $\mathrm{IV} / 28$ & $123^{\prime} 0 \mathrm{~mm}$ & $658^{\prime} 7$ & $18^{\prime} 6$ \\
\hline 1970 & $\mathrm{X} / 16$ & $42^{\prime} 0 \mathrm{~mm}$ & $354^{\prime} 1$ & $11^{\prime} 8$ \\
\hline 1971 & $\mathrm{X} / 6$ & $244^{\prime} 0 \mathrm{~mm}$ & $907^{\prime} 8$ & $26 ' 8$ \\
\hline 1972 & $\mathrm{III} / 1$ & $50^{\prime} 0 \mathrm{~mm}$ & $306^{\prime} 7$ & $16^{\prime} 3$ \\
\hline 1973 & $\mathrm{III} / 22$ & $91^{\prime} 7 \mathrm{~mm}$ & $831^{\prime} 6$ & $11^{\prime} 0$ \\
\hline 1974 & $\mathrm{X} / 26$ & $68^{\prime} 0 \mathrm{~mm}$ & $404^{\prime} 4$ & $16^{\prime} 8$ \\
\hline 1975 & $\mathrm{III} / 5$ & $87^{\prime} 0 \mathrm{~mm}$ & $487 ’ 2$ & $17^{\prime} 8$ \\
\hline 1976 & $\mathrm{~V} / 1$ & $47^{\prime} 0 \mathrm{~mm}$ & $415^{\prime} 0$ & $11 ' 3$ \\
\hline 1977 & VIII/27 & $61^{\prime} 0 \mathrm{~mm}$ & $759^{\prime} 4$ & $8{ }^{\prime} 0$ \\
\hline 1978 & $\mathrm{X} / 29$ & $85^{\prime} 0 \mathrm{~mm}$ & $527^{\prime} 0$ & $16^{\prime} 1$ \\
\hline 1979 & IX/19 & $43^{\prime} 0 \mathrm{~mm}$ & $366^{\prime} 3$ & $11^{\prime} 7$ \\
\hline
\end{tabular}

El cuadro anterior evidencia la importancia de las lluvias de extraordinaria intensidad que se producen en un número de días reducido al cabo del año y que determinan los valores totales y cambian el significado de las cifras medias.

Otra observación interesante es la de la distribución por meses de las precipitaciones y la frecuencia de los días de lluvia respecto de los distintos intervalos en $\mathrm{mm}$. Se aprecia con ello la preponderancia de los meses otoñales para las frecuencias mayores en los intervalos que son superiores a $30 \mathrm{~mm}$, incluso a $50 \mathrm{~mm}$, mientras que en los meses primaverales éstos son más reducidos para alcanzar su menor frecuencia en los meses invernales y por último en los estivales.

Las frecuencias mayores las presentan los meses de octubre, ya que en este mes se dan situaciones siempre ligadas a la depresión del Mediterráneo occidental que, unas veces por la presencia de gotas frías en [163] altura y, otra, por las advecciones superficiales, ponen en marcha el dispositivo succionador de la humedad mediterránea que, más tarde, precipitará sobre estas tierras ribereñas. Es, pues, el mes de octubre, el de máxima advección de aire mediterráneo 
sobre las costas de Levante, que motiva el máximo pluviométrico anual de la serie con una precipitación media de 109,06 mm que suponen el 20,05\% de la precipitación media anual de la serie, que es de 543,9.

Las advecciones zonales ligadas a fenómenos de gota fría producen las mayores precipitaciones, éstas son también características, además de su cuantía, por ofrecer una concentración de precipitación máxima en el tiempo. Este fenómeno de concentración máxima en el tiempo es de subrayada importancia para la zona que analizamos, puesto que los grandes volúmenes de precipitaciones caídos en un espacio de tiempo tan reducido coinciden con factores geológicos y biológicos (terrenos margosos y estado de Rhexistasia) que coinciden y ayudan a estas lluvias de gran intensidad horaria en su capacidad morfogenética. Hasta tal punto estos factores son concurrentes y activos que, en base a estos fenómenos pluviométricos puede decirse que se dan los cambios más patentes del relieve de la cuenca. Concretamente en el año 1971, en el mes de octubre, el día 6 se produjo una precipitación máxima en 24 horas con un total de $244,0 \mathrm{~mm}$ y que supuso el $26,8 \%$ respecto del total anual. Las precipitaciones que se recogieron en ese día fueron fruto de una situación advectiva zonal de Levante en superficie, con depresión en altura.

En los meses de invierno los efectos de estas gotas frías se reducen, y no porque sean menos frecuentes, sino porque han perdido la intensa inestabilidad característica de octubre, ello debido a la menor liberación de energía y a la disminución del contraste térmico entre las masas alóctonas y las mediterráneas. Igual ocurre durante la primavera, debido al desfase térmico de las aguas del Mediterráneo, aunque en este período siguen siendo efectivas.

El segundo máximo de invierno presenta las frecuencias mayores para los intervalos en mm más reducidos, esto se debe a que los fenómenos que proporcionan la mayor parte de las precipitaciones son las situaciones de borrascas atlánticas centradas, revitalizadas al llegar al Mediterráneo, que descargan las precipitaciones en totales reducidos, pero más espaciados en el tiempo.

Hasta ahora se ha hablado de precipitaciones sin concretar nada sobre su naturaleza. La inmensa mayoría de las precipitaciones tienen lugar en forma de lluvia $\mathrm{y}$, tan sólo, excepcionalmente, en forma de [164] nieve en la cumbre de la Sierra de Bernia ${ }^{17}$. En la zona costera (Moraira y Calpe) no aparecen días de nieve en todos los años que conforman el período elegido para efectuar este estudio climático. Este hecho se debe a que la temperatura media de todos los meses se mantiene por encima de $0^{\circ} \mathrm{C}$ y, además, la influencia reguladora del mar suaviza las temperaturas que en el entorno de Benisa y en la cumbre de Bernia son más rigurosas. El granizo no es abundante, pero los riesgos de granizada se dan frecuentemente, de manera especial entre los meses de diciembre a febrero, teniendo estas granizadas efectos desastrosos para la agricultura de la zona.

Las temperaturas.- El estudio de esta serie ha dado como resultado la existencia de una temperatura media anual para este período de $16,1^{\circ} \mathrm{C}$ (1969-79). La mayor parte de los años presentan registros térmicos medios que oscilan entre los 16 y $18^{\circ} \mathrm{C}$.

La oscilación máxima entre las medias anuales de la serie es de $2,4^{\circ} \mathrm{C}$. Así pues esta amplitud térmica interanual no es muy elevada, si bien en la costa todavía es más reducida en función del gradiente térmico de altura y por la influencia marítima.

El análisis del ritmo térmico anual nos muestra el mínimo común en enero, que presenta temperaturas de $7,5^{\circ} \mathrm{C}$ y el máximo térmico se produce en julio y agosto con 27 y $27,5^{\circ} \mathrm{C}$ respectivamente. Desde el mes de agosto empieza el declive térmico, que alcanza su tope en enero, como decíamos, comenzando en este mes la recuperación térmica que se hace

\footnotetext{
${ }^{17}$ Morales Gil. A.- Bru Ronda, C.- Box Amorós, M. (1982): «Algunos aspectos del modelado de la umbría de la Sierra de Bernia». En prensa. Pág. 15.
} 
paulatinamente superior en los meses invernales, con apenas un grado de diferencia, mientras que a partir de marzo este incremento térmico se hace más acusado, siendo de 3 ó 4 grados respecto del mes anterior.

La oscilación media posee un valor de $13,1^{\circ} \mathrm{C}$ entre el mes más cálido y el mes más frío. Esta oscilación también se puede observar a nivel de las temperaturas medias que presentan las distintas estaciones,

$\begin{array}{cccc}\text { Primavera } & \text { Verano } & \text { Otoño } & \text { Invierno } \\ 13 \text { '9 } & 22{ }^{\prime} 3 & 17{ }^{\prime} 3 & 10{ }^{\prime} 9\end{array}$

los inviernos suelen ser relativamente suaves y los veranos calurosos, mientras la primavera y el otoño son épocas de transición a las estaciones siguientes, siendo también estaciones benignas.

En cuanto a las temperaturas absolutas extremas, las máximas oscilan entre 31,4 y $40,5^{\circ} \mathrm{C}$ para el mes de julio de 1975 , mientras que la [165] mínima extrema fue de $-2,5^{\circ} \mathrm{C}$ para el mes de enero de 1971, dando como resultado una oscilación absoluta anual de $43,0^{\circ} \mathrm{C}$.

Hay que tener en cuenta que el período estudiado completo es de 11 años (1969-1979), habiéndose dado temperaturas mínimas extremas en el año $1956^{18}$, en el mes de febrero y que por lo tanto no entran en esta correlación por no existir datos.

Las temperaturas mínimas absolutas se registran en torno a febrero, y el mayor período de posibilidad de recibir heladas se extiende de diciembre a febrero, pudiéndose prolongar hasta abril.

La aridez.- Otro factor climático relacionado con las temperaturas y las precipitaciones, que cabe destacar, es la aridez o subaridez de este clima, que depara como consecuencia una vegetación rala y discontinua que no cubre las vertientes, exponiéndolas por ello a la acción morfogenética de las ramblas. Analizando el balance hídrico del clima de Benisa, presenta los períodos estacionales bien marcados. En primer lugar, se constata que a partir del mes de octubre el suelo empieza a acumular agua. Tal período abarca los meses de octubre y noviembre, iniciándose en diciembre un segundo período. Ahora el suelo ha retenido ya los $100 \mathrm{~mm}$ y no pudiendo acumular más cantidad permite obtener un superávit que circula por la superficie dando origen a los torrentes. En este momento, se inicia el tercer período, las temperaturas se han despejado y las precipitaciones se reducen considerablemente. Es necesario utilizar el agua de reserva, cuyo volumen se agota en los meses de mayo a junio, iniciándose, por tanto, el período árido o de déficit de agua, extendiéndose de junio a septiembre y presentando una cantidad de $340,85 \mathrm{~mm}$. El índice hídrico de este clima es de $-16,7$. Tal conclusión señala que pertenece al tipo $\mathrm{C}_{1}$ (seco subhúmedo). Su evapotransporación potencial es de $816,66 \mathrm{~mm}$, perteneciendo, por ello, al tipo $\mathrm{B}_{2}$ (mesotérmico). Sin embargo, dentro del tipo climático seco ha sido necesario averiguar el grado de humedad, alcanzando ésta un índice de 8,2 , indicando con ello que existe un pequeño exceso de agua (d) que se da en el período comprendido entre diciembre y abril.

Por último, la concentración de la eficacia térmica viene a demostrar que la misma es baja, siendo su valor de 46,80, lo cual pone de manifiesto que pertenece al régimen a'(megatérmico) y reflejando la influencia marítima de toda la costa mediterránea. En consecuencia el tipo climático para este área determinado por los índices de Thornthwate es $\mathrm{C}_{1} \mathrm{~B}_{2}{ }_{2} \mathrm{~d}$ a'.

En relación directa con el balance hídrico hay que destacar un hecho [166] que contribuye a acentuar la acción morfogenética de las ramblas, la no existencia de un tapiz vegetal continuo que proteja a este roqueado deleznable.

18 López Gómez, A. (1956): «Las heladas de febrero de 1956 en Valencia». Estudios geográficos. Tomo XVII, pp. 573-700. 
El bajo litoral del Mediterráneo está tapizado por la alianza Oleo-Ceratonion, representada por la asociación, en el sector de Alicante, Chamaeropeto Rhamnetum Lycioidis, debido al clima más xérico de este sector ${ }^{19}$.

No obstante y debido a la roturación que desde hace tiempo se ha ejercido en todo el sector y a la propia degradación de las especies, encontramos únicamente poblamientos ralos y discontinuos, muy abiertos, allí donde no se está cultivando. La Oleo-Ceratonion viene representada por matorrales formados por romerales y tomillares. Únicamente en los lechos de las ramblas la vegetación se condensa y aparecen colonizadas por especies de la alianza Tamaricion Africanae. Son frecuentes también los pinares de Pinus halepensis o pino carrasco, en los lugares donde los abancalamientos no existen.

Por último, el sector de montaña que comprende las máximas altitudes (Sierra de Bernia), presenta especies relictas de un dominio más húmedo ${ }^{20}$.

\section{EL SISTEMA DE DRENAJE}

Hay que comenzar diciendo que corrientes fluviales en el sentido pleno de la definición no existen en el sector, son ramblas mediterráneas de régimen intermitente y con peligro de avenidas.

Distinguiremos dos dominios de morfología fluvial, ambos con una dependencia marcadamente estructural. La red de drenaje muestra así dos tipos de cursos fluviales en los que la litología, las estructuras, la geotectónica, y la climatología están en una estrecha interdependencia, y han conformado sendas morfologías. Diferenciamos, pues, a una serie de torrentes que tienen su origen en el retablo montañoso, de un conjunto de ramblas que nacen en el sinclinal margoso de Benisa-Teulada a la altura del altiplano. Ambos sistemas apuntan a dos fases cronológicas distintas, por lo que hablaremos de una red primitiva y de una nueva red de ramblas.

\section{LA RED PRIMITIVA}

Alude a los torrentes que atraviesan el retablo montañoso y que aparecen, [167] en líneas generales, decididos por las estructuras anticlinales que presentaban unas líneas de fracturas (subyacentes en los materiales cretácicos y reactivadas por la eclosión diapírica en los materiales terciarios oligocenos), que son fallas de distensión normales y post-orogénicas debidas al reajuste de finales del Mioceno, y que poseen una dirección generalmente NW-SE. Los torrentes aprovechan en la mayoría de los casos estas fracturas.

Para la reconstrucción del trazado de sus cauces se ha utilizado el mapa topográfico 1:50.000 y la fotografía aérea del vuelo de 1978, esc. 1:18.000, esta última ha sido realmente esclarecedora ante el poco detalle del topográfico.

Bco. del Puig de Benitachell.- En una breve descripción de los cursos encontramos de $\mathrm{E}$ a W una serie de torrentes que descienden del Puig de Benitachell y la Llorengá. Aparecen aquí dos tipos de corrientes ligadas a épocas distintas. Por una parte, la deformación finicretácica produjo una línea de fractura que fue aprovechada por un valle ortoclinal, originándose una corriente subsecuente a la estructura cretácica y que abre, a modo de pasillo, un corredor entre estructuras cretácicas y oligocenas. Este pasillo ortoclinal se conoce en la zona como el Barranco de la Cala, el cual presenta unas paredes verticales y abruptas, siendo éste sólo transitable a

\footnotetext{
${ }^{19}$ Bellot, F. (1978): El tapiz vegetal de la Peninsula Ibérica. Ed. Blume. Madrid. Pág. 179.

${ }^{20}$ Morales Gil, A. et alter (1982). Op. cit. pág. 20.
} 
través de la boca del corredor. En el extremo SE se abre al mar, en el Portet, conformando una pequeña caleta cubierta de cantos que ponen de manifiesto el funcionamiento, en otra época, de este torrente ortoclinal que ya a finales del Pleistoceno no realizaría una función tan vigorosa.

Los otros torrentes, con dirección NW-SE, son consecuentes a las estructuras y aprovechan, al igual que los barrancos de Aullera y de l'Horta, que luego veremos, las fracturas producidas en las estructuras a finales del Mioceno. Son corrientes cataclinales que atraviesan las crestas anticlinales del Oligoceno fracturadas. Estos torrentes no muestran un gran desarrollo por descender rápidamente al sinclinal mioceno y ser jerarquizados aquí por la rambla principal que desagua en la bahía de Moraira (el Barranco de Moraira) y ni siquiera reciben nombres de barrancos. Estos cursos estructurales ven reducida la extensión de su cauce a la de las fracturas y raramente muestran, hoy, una circulación superficial, ya que durante las escasas precipitaciones no acumulan suficiente caudal como para manifestarse, y la precipitación caída en los chubascos es absorbida rápidamente por este roquedo calizo muy permeable y diaclasado.

Bco. de Benitachell.- Hacia el NW encontramos otro curso, el [168] Barranco de Benitachell, que al $\mathrm{NW}^{21}$ de este municipio nace en la partida de Benicambra, y con una dirección SW-NE atraviesa las estribaciones del Tosal Gros, Coatelles y los Altos del Rebaldí-Las Capsades a través de un collado entre estas estructuras que abre esta cuenca miocena hacia el sinclinal mioceno de Jávea, situado al NE del sector que estudiamos.

Este barranco de Benitachell tiende a ser capturado por una rama del Barranco de las Fuentes, que retrocede desarrollándose desde la costa de Moraira con dirección N-S a partir de la divisoria de aguas, en la cota de $165 \mathrm{~m}$ en el Cerro Blanco. Otra rama de este mismo Barranco amenaza al Barranco de Benitachell en la partida de los Molinos próxima a Teulada por el SE. La extensión de su cauce abarca $4,320 \mathrm{Km}$, mostrándose actualmente este curso como paleocanal sin funcionamiento hídrico externo, colgado a los $150 \mathrm{~m}$ de altura en el altiplano Teulada-Benitachell. En la confluencia con el río Jalón, se aperciben restos de terrazas posiblemente en dos niveles distintos. Este curso, al igual que los que describiremos a continuación, tienen o tenían su nivel de base en el río Jalón, al NE y fuera de la cuenca que analizamos.

Bco. de L'Horta.- Separado del Barranco de Benitachell por un cerro que culmina a los 245 $m$ al NE de Teulada, encontramos el Barranco de L'Horta, que aguas abajo recibe el nombre de Barranco de Teulada. Desarrolla su curso a lo largo de $8,750 \mathrm{Km}$ y cruza con dirección S-N el Collado de la Sierra de Soldetes, por la Garganta de Gata, hasta desaguar en el Gorgos o Jalón, realizando un descenso desde el Pla del Feliu, a los $200 \mathrm{~m}$ hasta los $60 \mathrm{~m}$ en que confluye con este río. Este curso configura asimismo un paleocanal colgado en el altiplano de Teulada y que tiende a ser capturado por la nueva red de ramblas.

Bco. de la Garganta.- En la trayectoria hacia occidente encontramos el Barranco de la Garganta, que entre el Pico de Serrella y la Sierra de Castellar se desarrolla en un primer tramo de $\mathrm{E}$ a W para luego girar y discurrir de $\mathrm{S}$ a $\mathrm{N}$ hacia el río Jalón, en la depresión de la Solaneta. Posee una rama más joven por la disección que muestra, que con dirección S. a N. atraviesa en su cabecera entre el Tosal del Cosi y las Peñas Blancas una falla estructural, para configurar en la vertiente sur una depresión estructural denominada «la Foya». En este sector el Barranco recibe el nombre de Barranco de la «Aullera» y queda colgado en una depresión a los $260 \mathrm{~m}$ al NE de Benisa.

Como se ha descrito estos tres últimos barrancos poseen unas características peculiares, ya que todos ellos tienen su nivel de base en [169] el río Jalón o Gorgos, y han configurado en sus cabeceras una topografía antigua colgada en torno a los 200/220 m de altitud sobre el nivel

\footnotetext{
${ }^{21}$ Nombre que se le dio porque pasan cerca de este núcleo poblacional, y no viene representado en el topográfico 1:50.000 con ningún nombre.
} 
del mar, dando lugar a unos antiplanos que reciben los nombres de Pla de los Molinos y la Foya al W de Benisa, y al E, Pla de Bonaire, y en el término de Teulada al N, Pla del Feliu. (Ver gráfico).

Son unos paleocanales que presentan un cauce de fondo llano, muy evolucionados, y que drenan hipágeamente los llanos de Teulada y Benisa, a los cuales configuran. El motivo de estas formas que hoy se nos muestran está en los fenómenos de la tectónica post-pliocena que afectaron la vergencia de estos torrentes que afluían al río Jalón hacia el NE, y modificaron el nivel de base y por lo tanto el drenaje de las vertientes. Pudo asimismo favorecer una obstrucción relativa al drenaje, la barra estructural de la Sierra de Castellar (al N) que con las pulsaciones post-pliocenas pudo entorpecer al desagüe de estos barrancos. Otro hecho a destacar es que el río Jalón se encuentra en su tramo final y desembocadura, en la Bahía de Jávea, entre dos sectores de distinta tendencia, al $\mathrm{N}$ del paralelo de Denia ${ }^{22}$ y de su desembocadura, se instala una costa de subsidencia, mientras que al sur encontramos una costa de emersión. El profesor Rosselló expone que «aunque actualmente parece más plausible inclinarse por la emersión de la zona de la recalada de Xàbia, en el sector del Cabo de San Antonio se localizan rasas sumergidas, que pueden obedecer a fenómenos de subsidencia local $»^{23}$.

Todo ello podría explicar el perjuicio de la vertiente que desagua hacia el río Jalón a favor de la nueva red de ramblas del sector de Moraira-Calpe, donde las mayores pendientes han favorecido una erosión remontante más eficaz desde la costa inmediata, y que tiende a disecar rigurosamente en algunos sectores topografías arcaicas de los altiplanos colgados.

Bco. del Estret.- Otro curso que nace en el retablo montañoso y que es netamente estructural es el Barranco del Estret, que en cabecera recibe el nombre de Barranco del Guillem, y cuando desemboca, Barranco del Mascarat. Nace en la vertiente $\mathrm{N}$ de Bernia, y cruza a ésta en dirección NW-SE a través de una falla, tras la cual adopta una dirección NE-SW, discurriendo pegado a la falla NW de Bernia, donde diseca en su recorrido el contacto margoso del sinclinal mioceno con la estructura anticlinal de la sierra, para desaguar a través del tajo del Mascarat, en la costa de Altea, donde desarrolla una pequeña playa de cantos.

Este curso que cambia de orientación, en ambos casos lo hace siguiendo [170] una línea de debilidad, y la dirección perpendicular que adopta en su segundo tramo, y que sigue la línea de la falla del Mascarat, le ha permitido la evacuación directa de este curso fluvial hacia la costa inmediata, donde se ubica su cono de deyección.

El desarrollo de su curso a lo largo de $8 \mathrm{Km}$, como el encajamiento que realiza en su tramo medio y final, es mucho más espectacular que en los casos anteriores, lo que se debe en parte a que aprovecha la falla de gran envergadura que separa Bernia del mogote eoceno deslizado de Oltá, y socava por la base de este anticlinorio calizo, que flota sobre las margocalizas, al igual que aprovecha la falla del Mascarat, en el anticlinal de Bernia para salir al Mediterráneo. Este nivel de base más cercano ha propiciado de igual forma una acción erosiva más potente al tener que salvar unas pendientes más acusadas $\left(70 \%_{0}\right)$ en un corto espacio, prueba de ello es el abundante material aluvial de cantos que tapizan el lecho del barranco.

\section{LA NUEVA RED DE RAMBLAS}

El sistema de drenaje, que actualmente se manifiesta en superficie, corresponde a la «nueva red de ramblas» que se formó a raíz de la tectónica post-pliocena. Esta etapa posterior a la distensiva provocó el basculamiento del sinclinal margoso, originando una divisoria de aguas

\footnotetext{
${ }^{22}$ Rosselló Verger, V. M. (1978). Op. cit. pág, 20.

${ }^{23}$ Rosselló Verger, V. M. (1979). Op. cit. pág. 93.
} 
en el sinclinal extendida de NE a SW, a partir de la cual se instaló esta nueva red fluvial, que discurriría hacia la vertiente $S$ en dirección opuesta a la primitiva red. Estas ramblas se instalaron en el sinclinal mioceno sobre rocas fácilmente erosionables, coincidiendo, en ocasiones, con líneas de debilidad en los paquetes margosos, producidas en un primer momento con la tectónica distensiva post-miocena y que sin embargo no había afectado al mioceno, prolongándose bajo él, y ahora en esta última etapa orogénica y posteriormente en el post-plioceno serían reafirmados. A estos factores estructurales se añaden los geológicos y los climáticos, que van a favorecer la permanencia, hasta hoy, y el gran poder erosivo de estas ramblas.

Bco. de Moraira.- De E a W en primer lugar encontramos elBarranco de Moraira, que nace en la divisoria de aguas entre el altiplano y la cuenca miocena, a la altura de $160 \mathrm{~m}$ al SE de Teulada, y desciende de $\mathrm{N}$ a $\mathrm{S}$ hacia la costa trasversal. Presenta cuatro ramas principales: el Barranco Rojo, de dirección N-S; el Barranco de la Casa de Blanco, dirección N-S; Barranco de las Fuentes, NW-SE; y Barranco de los Pasos, W-E, esta última rama por el W encuentra una nueva divisoria hacia la cuenca de Benisa y Calpe, donde forma un codo de captura con el Barranco L'Horta, descrito anteriormente. La captura la encontramos [171] siguiendo la línea divisoria de aguas que marca la carretera de Benisa a Benimarco y Teulada, en la cota de los 200 $\mathrm{m}$, donde el Barranco de los Pasos, afluente del de Moraira por el W, tiende a capturar al paleocanal del Barranco de L'Horta, en la Partida de Benimarrach. El Barranco de los Pasos se extiende perpendicularmente a la dirección del Barranco de L'Horta, pero el codo no queda configurado aún, quedando retenido por la acción antrópica que regula las pendientes ostensiblemente.

El Barranco de Moraira recibe además por el E las aguas que ocasionalmente vierten los torrentes cataclinales que descienden del Puig de Benitachell. Posee un desarrollo en el cauce mayor de unos $6 \mathrm{Km}$ y salva fuertes pendientes, con un desnivel medio del 31 por mil. Presenta en su tramo final, a la altura de la Ermita de la Font Santa, donde la pendiente se reduce bastante, restos de hasta tres niveles de terrazas.

Bcos. del Baladrar y «dels Avencs».- Siguiendo hacia el W frente a la costa del Baladrar y a $3 \mathrm{Km}$ del mar, trasversalmente a él, se desarrolla otra serie de barrancos de menores dimensiones que el anterior. Parten igualmente de un saliente que realiza la divisoria de aguas y amenazan de manera apremiante al Barranco de L'Horta de Teulada. Son dos barrancos, el del Baladrar y el de Avencs. Ambos en un recorrido abrupto descienden desde los $200 \mathrm{~m}$, o pocos más, en la Partida de Benimeic y Fanadix, donde el Tosal de Conside y el Tosal dels Avencs realizan la separación entre las dos vertientes. A partir de aquí se inicia una abrupta pendiente del 81 por mil que es disecada por estas ramblas hasta desaguar en la cota de $0 \mathrm{~m}$ en el mar. El desagüe de los dos barrancos es paralelo y se realiza a través de una cala tapizada de cantos.

Este sector descrito queda separado del que se sucede más a occidente por una serie de lomas, como la de Mosén Pérez, del Teder, etc., que se levantan hasta los $259 \mathrm{~m}$ y que son disecadas en su vertiente occidental por otra red de ramblas que descienden desde la divisoria de aguas al pie del altiplano de Benisa.

Bco. del Quisi.- Encontramos aquí al W del sinclinal el aparato hidrológico más desarrollado, que desciende desde el altiplano de Benisa a los $260 \mathrm{~m}$ hasta la costa frente a Calpe, con un desarrollo de $8 \mathrm{Km}$ en los Barrancos del Quisi y del Conquet, que aguas abajo se unen y forman el Barranco del Pou Roig. En este colector la amenaza de capturas a la red primitiva se pone de manifiesto en la rama oriental del Barranco del Quisi, que a la altura de les Albes $(255 \mathrm{~m})$ y cerca de la Estación de ferrocarril de Benisa inicia un trasvase de agua, desde una rama del Barranco de L'Horta en el altiplano de Teulada hacia la vertiente litoral miocena en la costa de Calpe. A diferencia del caso anterior, las alineaciones de los cursos de los barrancos siguen el mismo de la circulación, [172] aunque las direcciones sean contrarias, y aprovecha el Barranco del Quisi justamente la excavación que se ha hecho en el túnel del 
ferrocarril, que se instala en una depresión endorreica del paleocanal del Barranco de L'Horta, por lo que realiza la función de sumidero para las aguas que aquí pudieran retenerse y que pueden pasar de la vertiente $\mathrm{N}$ a la sur.

Por la margen derecha del Barranco del Quisi, este colector amenaza constantemente al Barranco de la Hortá, ya que la acción erosiva remontante que se establece en las ramas laterales del Barranco del Quisi es muy fuerte al salvar estas ramas, en este sector, alturas considerables en pocos kilómetros dando pendientes del sector del 200 por mil.

El Barranco del Quisi y el del Conquet han limitado la extensión y desarrollo del pueblo de Benisa hacia el sur y le han obligado a desarrollar una morfología de pueblo calle que se instala sobre la misma divisoria de aguas y eje de basculación del sinclinal, (SW-NE) entre el altiplano y el valle mioceno excavado. Al sur de Benisa se adivina igualmente otro proceso de captura que se establece entre el Barranco del Quisi y una rama del Barranco de la Garganta (el Barranco de la Aullera) en la vertiente N, pero ésta es menos manifiesta que la de los anteriores casos.

Pertenecientes a este mismo colector encontramos los Barrancos del Conquet y del Vicent, afluentes por la margen izquierda que lamen y disecan el piedemonte $\mathrm{W}$ de la Sierra de Oltá. El Barranco del Quisi presenta unos depósitos de terrazas que posiblemente pasen lateralmente a ser glacis-terrazas por encontrarse restos de una superficie glacificada, esto ocurre a unos 2,5 Km de la costa, una vez pasados los altos de Llombers.

Morfogénesis fluvial.- Los dos tipos de redes fluviales que se han descrito han configurado dos tipos de paisajes morfológicos bien diferenciados.

En el caso de la red primitiva, de haber continuado la acción morfogenética vigente, ésta hubiera sido considerable, ya que los trazados relictos de los cauces muestran unos desarrollados cursos que así lo confirman, pero la deformación post-pliocena que dio lugar a la nueva circulación en la vertiente sur produjo una reducción efectiva de la capacidad morfogenética de éstas, y favoreció la configuración de estas topografías arcaicas colgadas entre los 200 y $220 \mathrm{~m}$ sobre el nivel del mar.

La nueva red que a partir de la divisoria de aguas comenzó a fluir con dirección N-S, y perpendicularmente a la costa, originaría una topografía muy distinta a la anterior, y esto debido a una serie de premisas que coincidentes van a favorecer el vaciado del sinclinal mioceno. Así, la presencia de unas pendientes en general superiores al 30 por mil, [173] de una litología propicia a ser erosionada (margas y margo-calizas no permeables), una cobertura vegetal rala y discontinua en estado de Rhexistasia, así como la concurrencia de un clima con violentos chubascos de fuerte intensidad horaria, separados por largos períodos de sequía, que contribuyen a degradar la cobertera vegetal, ya que los terrenos se agrietan. Todos estos hechos propician el ambiente idóneo al progreso de estas ramblas que erosionan el sinclinal y a los fenómenos de capturas que sustraen poco a poco espacio a la superficie allanada de los paleocanales.

La acción de estas ramblas se ha desarrollado desde el Pleistoceno, probablemente con un gran poder erosivo durante los interglaciares, en base a un clima árido y que, similarmente a las actuales condiciones, favoreció los arrastres, y posibilitó las formaciones tirrenienses (en este sentido Novo Chicano ${ }^{24}$ cree que los cordones relictos de la zona de Jávea y de «les Rotes» de Denia proceden del material de denudación del Mioceno del Llano de Denia, y del sinclinal de Benisa). Si bien durante la última regresión Würm existió una modesta erosión de las ramblas ${ }^{25}$; ya en el Holoceno y tras la trasgresión Flandriense, postglaciar, el poder erosivo de estas ramblas

${ }^{24}$ Novo Chicharro (1915), cit. en: José Costa Más (1977) El Marquesat de Denia. Estudio Geográfico. Univ. de Valencia. Pág. 23.

25 Rosselló Verger, V. M. (1979): «Las calas: un tipo de costa peculiar mediterránea». Primer curso de Geomorfología litoral aplicada. Univ. Politécnica de Valencia (ETSICCP), Valencia. Pág. 108. 
debió acentuarse, coincidiendo con este momento, posiblemente, el proceso de formación de las capturas. Posteriormente la progresiva aridez que parece haberse producido, (dentro del Holoceno aluvial en que hoy nos encontramos) haya favorecido desde diferente óptica morfogenética la capacidad de estos colectores.

Un hecho a destacar en este sentido es la lucha continuada que se viene ejerciendo desde época histórica contra la acción devastadora de las aguas de arroyada.

Ya en tiempos de los árabes, se empezaron a regular las vertientes de los barrancos en puja contra este fenómeno, y se hizo mediante la construcción de muretes de mampostería que retenían estos suelos margosos. Igualmente vemos cómo Cavanilles describe una zona del sinclinal en Teulada, y dice: «hacia el mar en el distrito llamado Pedra Mala excavaron las aguas en los campos cultivados un ancho barranco cuya capacidad va aumentando en perjuicio de los campos contiguos; sus ribazos son de marga blanquecina hasta la profundidad de diez pies, siguiéndose hacia abaxo un banco de cantos rodados que forman como tres pies [174] de espesor, el cual descansa sobre otro más grueso de tierra.... ${ }^{26}$. Se desprende pues que toda esta vertiente $\mathrm{S}$, de pendientes abruptas, haya sido continuamente regularizada para su aprovechamiento agrícola a pesar de que una avenida abría boquetes, llevándose en sus crecidas lo que encontraba a su paso, incluidos estos aterrazamientos artificiales que trataban, además, de retener el agua fortuita, ante la escasez de dicho elemento.

Los habitantes del pueblo de Moraira recuerdan, como hecho insólito, que el año 1958, en el mes de octubre, el Barranco de Moraira, que desagua en la ensenada de dicho pueblo, bajaba lleno de orilla a orilla, en un lecho de inundación que en la actualidad posee una anchura aproximada de $1 \mathrm{Km}$ en su canal de desagüe, y éste arrasó árboles, cultivos, casas, y cuentan que vieron bajar a mulos, perros y otros animales arrastrados por estas aguas. El pueblo, ubicado en la parte lateral izquierda del cauce en su desembocadura, sufrió inundaciones y no se distinguía donde comenzaba el mar y terminaba el barranco. Esta anécdota puede tener relación con el registro climatológico que se tiene para ese año de 1958, donde en el mes de octubre se registró $123,0 \mathrm{~mm}$ en el día 27 del mismo.

En este sentido el profesor Rosselló dice: «a ciertos efectos geomórficos, la irregularidad, el desequilibrio, es muchas veces más trascendente que los valores medios: unas horas de crecida pueden modificar más el paisaje que decenas de años de escorrentía normal» ${ }^{27}$.

Ante esto hay que recordar que el análisis climático del sector ha puesto de manifiesto el carácter irregular del clima. No obstante el proceso humanizador de todo el sinclinal, en el que se desarrollan estas ramblas, ha sido impresionante, de forma que el abancalamiento realizado ya desde antaño y mantenido incluso actualmente (en virtud de la pervivencia del cultivo del moscatel), ha regularizado el aparato hídrico y las vertientes, impidiendo estas acciones morfogenéticas tan activas. Al igual, ha contribuido a retener el proceso morfológico de las capturas.

\section{ESTUDIO MORFOMÉTRICO \\ DE LA CUENCA-SECTOR NUEVA RED DE RAMBLAS}

Descritos ya ambos tipos de cursos, se ha hecho un estudio de la red [175] referido a los cursos más desarrollados y más directamente relacionados con el proceso de las capturas, es decir, los Barrancos del Quisi y de Moraira. No hay que abandonar la idea de que sin constituir

\footnotetext{
${ }^{26}$ Cavanilles, A. J. (1797): Observaciones sobre la Historia Natural, Geografia, Agricultura, Población y Frutos del Reino de Valencia. Madrid, Imprenta Real, Tomo II, pág. 23.

${ }^{27}$ Rosselló Verger, V. M. (1972): «Los ríos Júcar y Turia y la Albufera de Valencia». Cuadernos de Geografia, $\mathrm{n}^{\circ} 11$. Univ. de Valencia, Pág. 11.
} 
un único colector vacían entre ellos una misma cuenca vertiente, aunque ésta sea una cuenca reducida, $89,12 \mathrm{Km}^{2}$.

Para el estudio de la red fluvial se ha hecho según las normas de A. N. Strahler ${ }^{28}$ y se ha realizado la morfometría sobre la base planimétrica de la fotografía aérea del vuelo del 78, escala 1: 18.000. (Ver gráficos 2 y 3).

La cuenca que se extiende al sur de Benisa-Teulada abarca una superficie de $89,12 \mathrm{Km}^{2}$, por lo que puede considerarse una cuenca pequeña, al igual que las subcuencas que se insertan dentro de ellas, por lo que los contrastes entre distintos parámetros pueden agudizarse, al igual que influye directamente sobre el orden del cauce principal. No por ello la cuenca deja de estar bastante desarrollada para lo reducido de su superficie, ya que alcanza el orden 4 para la subcuenca del Barranco de Moraira, y del orden 5 para el Barranco del Quisi. Este desarrollo de la cuenca tiene una relación directa con la litología y la acción morfogenética de los chubascos de fuerte intensidad horaria.

El número de cauces de los distintos órdenes representan 41 para el Baranco Rojo, y 108 para el Barranco del Quisi. En ambos cursos la profusión de cursos se concentra en la orilla izquierda y derecha respectivamente, coincidiendo con el centro del sinclinal, es decir, con una litología apta para el desarrollo de las ramblas, y allí las pendientes son mayores, mientras que en los sectores laterales de $\mathrm{E}$ y $\mathrm{W}$ en contacto con el arco estructural montañoso los cauces que aparecen están claramente decididos por las estructuras sobre una litología calcárea, y no se prodigan y ramifican tanto.

El desnivel de la cuenca es para el Barranco de Moraira de $240 \mathrm{~m}$ en 5,5 Km, con una pendiente de 43 por mil; y para el Barranco del Quisi de $260 \mathrm{~m}$ en 7,5 Km, con un desnivel del 34 por mil. Otro parámetro a tener en cuenta es la densidad de drenaje, que es de $2,41 \mathrm{Km} / \mathrm{Km}^{2}$ para el primero, y de $2,79 \mathrm{Km} / \mathrm{Km}^{2}$ para el segundo. Densidades de drenaje relativamente altas, y muy vinculadas a las litologías de textura grosera e impermeable (margas).

La razón de bifurcación, o ley del número de cauces, establece que «el número de segmentos de órdenes sucesivamente inferiores de una cuenca dada tiende a formar una progresión geométrica que comienza con el único segmento de orden más elevado y crece según una relación [176]

CARACTERISTICAS DE LAS CUENCAS DE DRENAJE

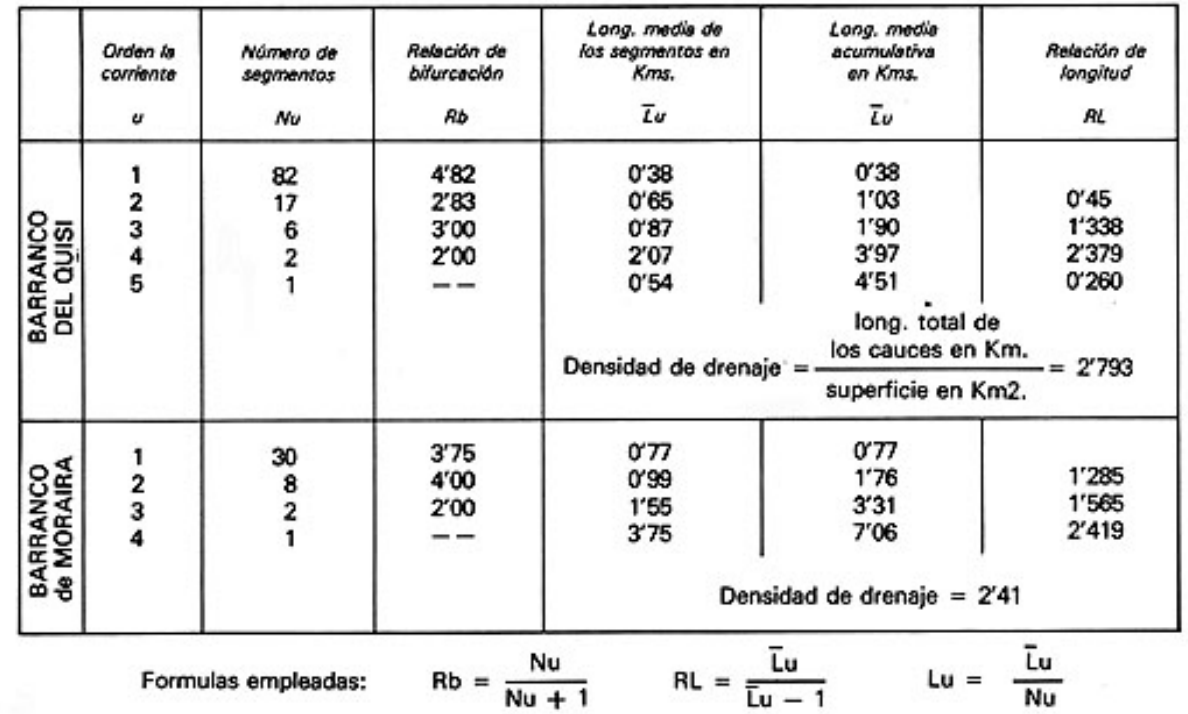

${ }^{28}$ Strahler, A. N. (1957): Geografia Física. Ed. Omega. Barcelona. Trd. 1974. Págs. 521-539. 
[177]

constante de bifurcación» ${ }^{29}$. El valor medio de la bifurcación es de 3,25 para el Barranco de Moraira y de 3,16 para el del Quisi, un valor relativamente bajo que nos indica la relación existente con la redondez de la cuenca. A estos valores bajos de bifurcación corresponden riesgos de inundaciones por crecidas momentáneas.

Por último, la razón de longitud (ver cuadro) establece que la longitud media de los cursos se incrementa entre 2 y 3 veces cada vez que aumenta el número de orden, y sirvió a Horton para formular la ley de longitud de los cursos, en la que se establece que la longitud media de los cursos de un orden dado en una cuenca se incrementa sistemáticamente con el incremento del orden del curso. En el caso del Barranco del Quisi el valor modal de 0'260 que presenta en su último orden viene referido a la confluencia en el curso más bajo, a pocos kilómetros de la costa, de dos ramas principales que configuran este $5^{\circ}$ orden, pero que debido a las dimensiones reducidas de la cuenca no ofrece este incremento sistemático que enuncia Horton.

El drenaje y la escorrentía.- Por no constituir auténticos cursos de agua no existe ninguna estación de aforo que pueda ofrecernos datos sobre el caudal y su regularidad, factor que impide de momento evaluar igualmente la salida («output») de materiales sólidos de la cuenca. No existen tampoco embalses en la zona, por lo que únicamente contamos con los datos pluviométricos expuestos en los cuadros y que hablan de aportes diarios, mensuales y estacionarios.

A resaltar es el hecho de la problemática de las crecidas que, como se ha señalado, con carácter destructivo amenazan la estabilidad de las vertientes, y de las cuales tenemos reseñas históricas. Hay que tener en cuenta además que estos cursos únicamente ven circular corrientes de agua en los días en que con ocasión de precipitaciones de fuerte intensidad horaria se da una abundante lluvia en un reducido tiempo que el sustrato geológico no absorbe y por lo tanto evacua, por lo que es paralelo el proceso de circulación y crecida, y coinciden estos días con los de fuerte acción morfogenética de las ramblas, siendo en ambos sentidos contabilizables entre 5 y 10 veces al año en los que circulan las ramblas. En este aspecto hay que añadir que las dimensiones reducidas de la cuenca, la litología predominantemente margosa, la escasez de lluvias registradas en la zona, originan un tipo de aparato hídrico propio de las ramblas de zonas áridas.

Alicante, Septiembre 1982

${ }^{29}$ Horton, R. E.: en A. N. Strahler. Op. cit. Pág. 525. 


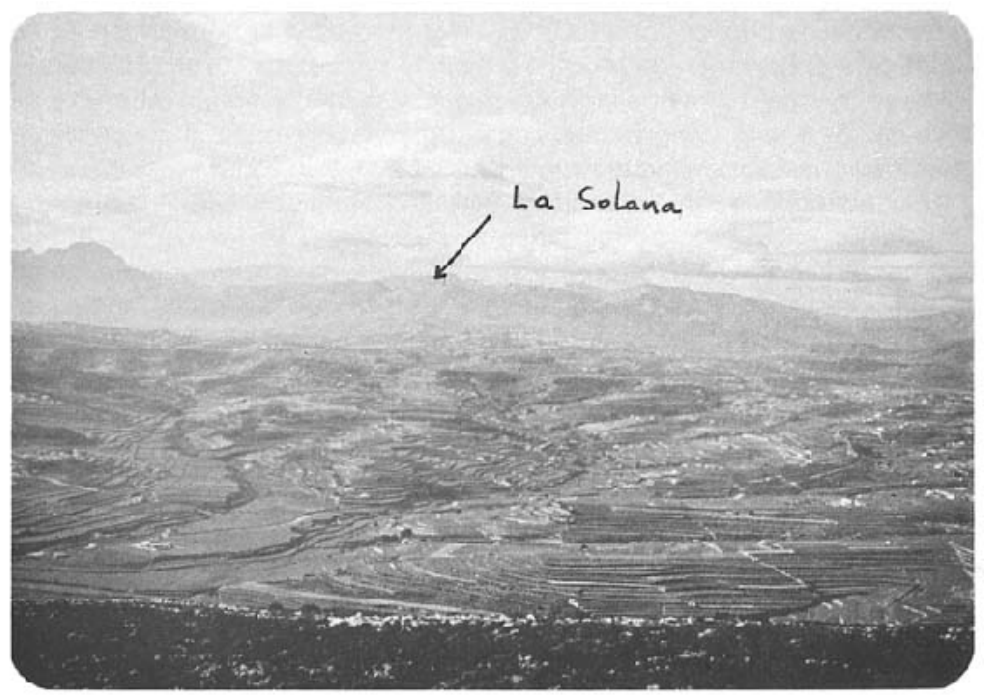

Retablo montañoso y disección fluvial sobre el sinclinal mioceno.

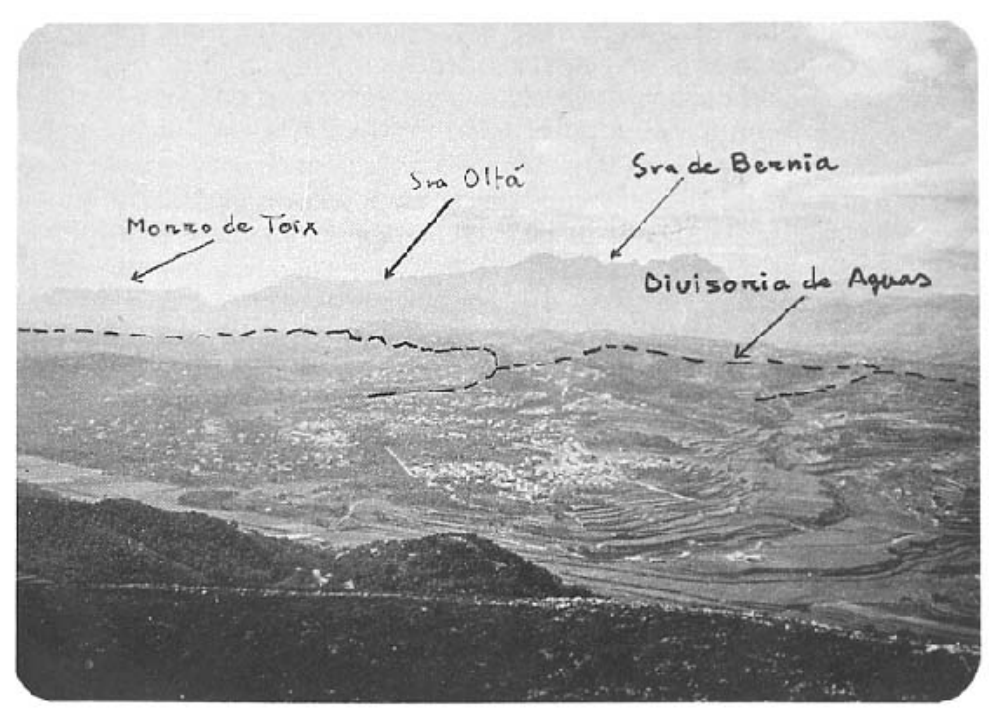

Divisoria de aguas en el sinclinal. 


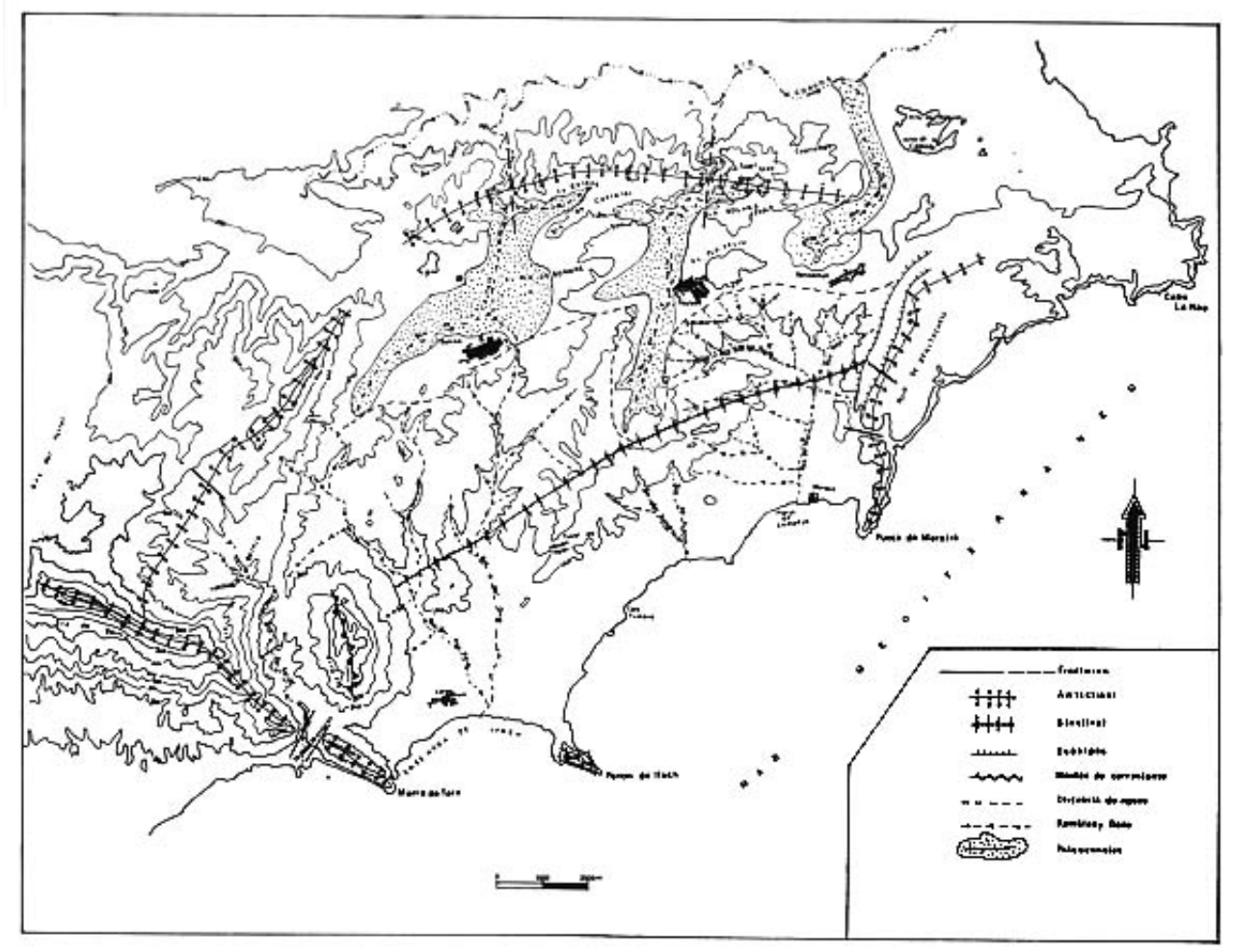

GRÁFICO 1 - MAPA MORFOLÓGICO

IX

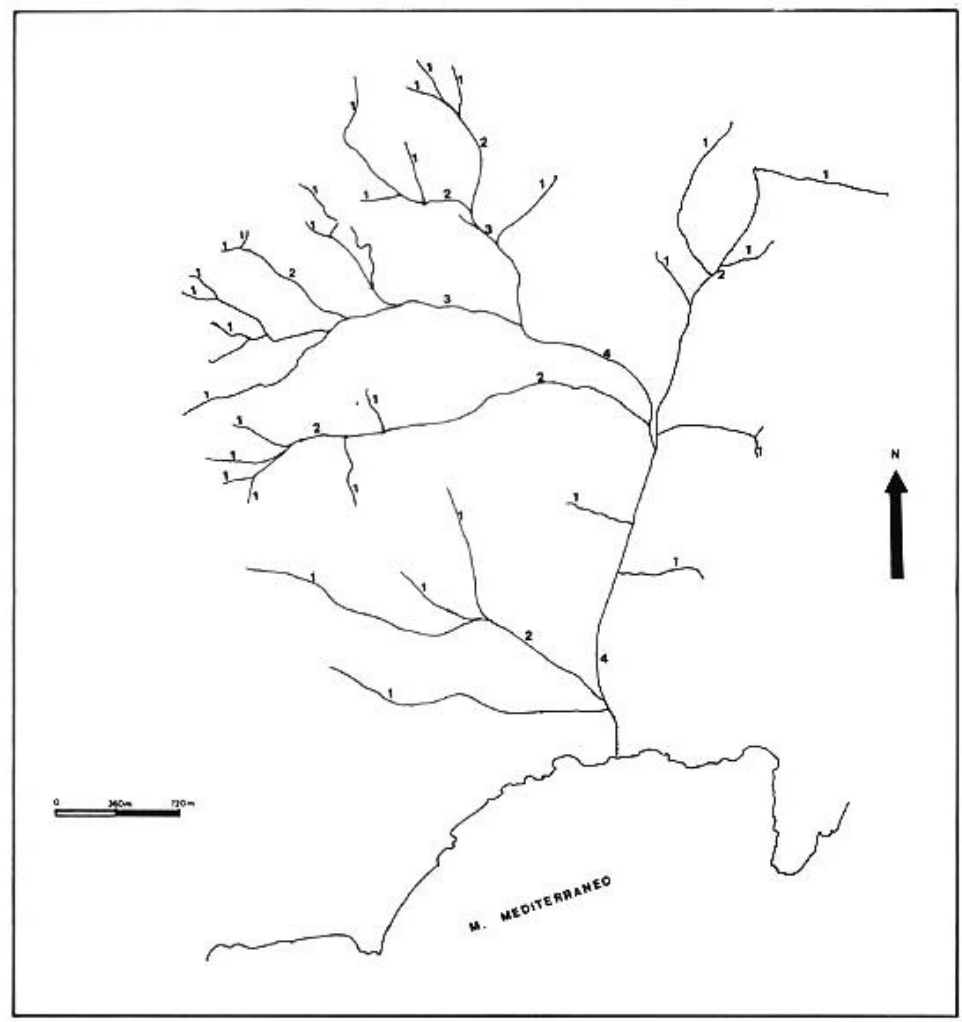


GRÁFICO 2 - BARRANCO DE MORAIRA. ÓRDENES DE LOS CAUCES SEGÚN STRAHLER. $\mathrm{X}$

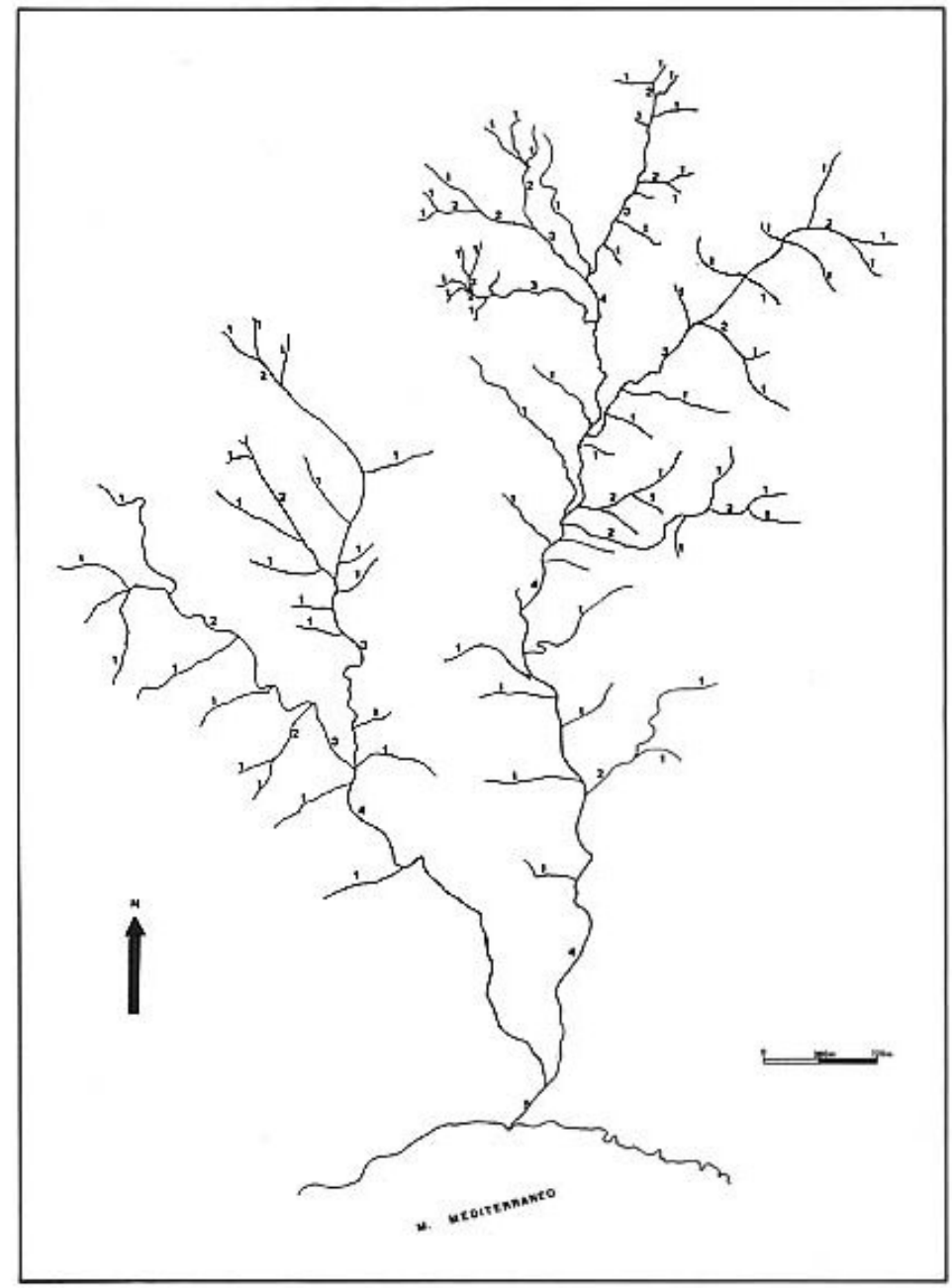

GRÁFICO 3 - BARRANCO DEL QUISI. ÓRDENES DE LOS CAUCES SEGÚN STRAHLER.

$\mathrm{XI}$

[179] 


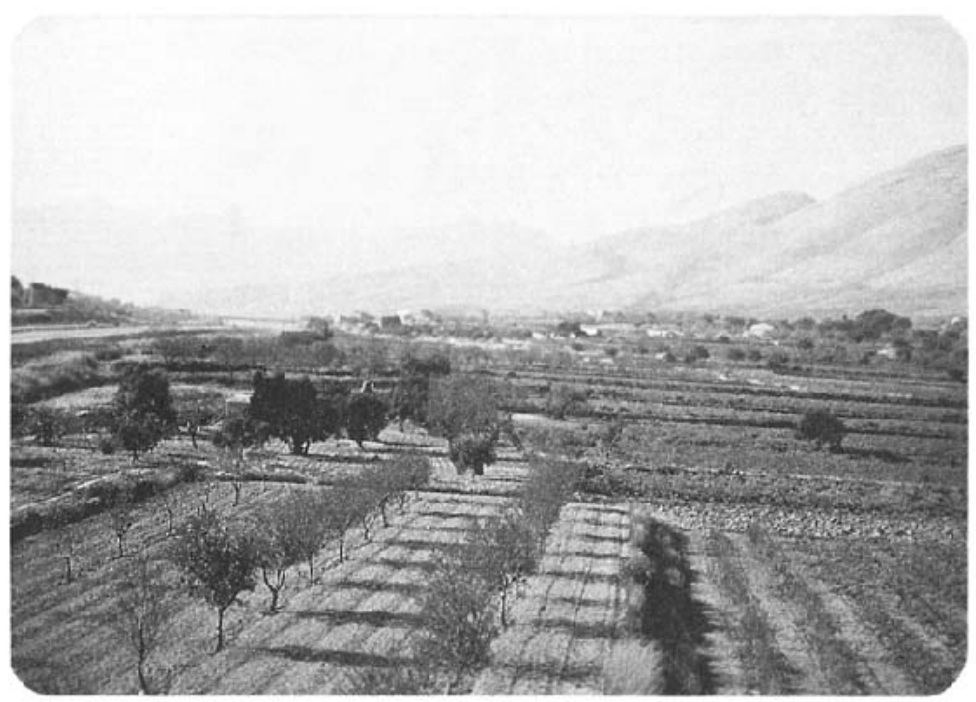

Paleocanal transformado para el cultivo.

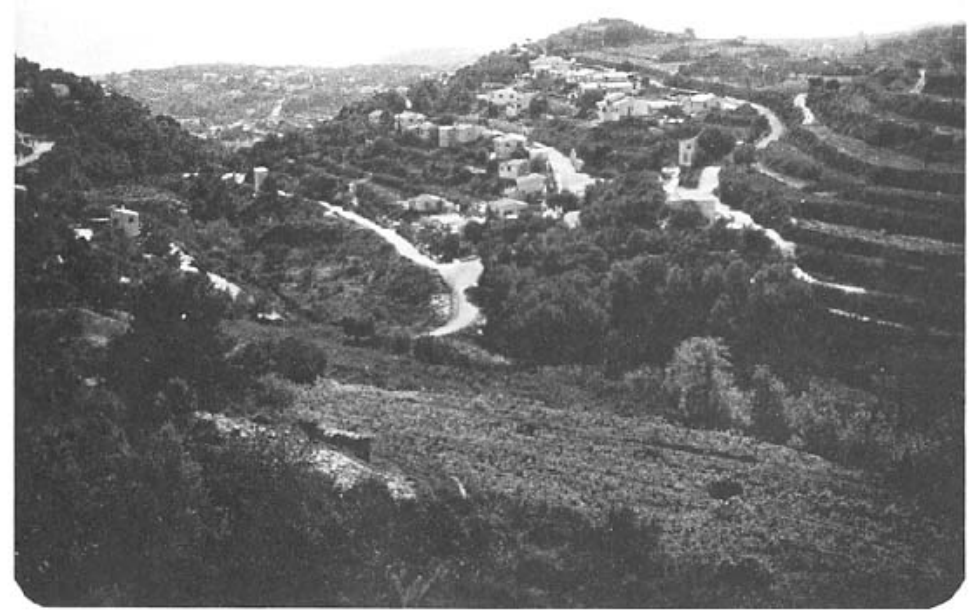

Rama lateral del Bco. del Quisi en la que se aprecian las fuertes pendientes. 